\title{
Immune checkpoint inhibitors in oncogene-addicted non-small cell lung cancer: a systematic review and meta-analysis
}

\author{
Giorgia Guaitoli $^{1,2}$, Marcello Tiseo ${ }^{3,4}$, Massimo Di Maio ${ }^{5}$, Luc Friboulet ${ }^{2}$, Francesco Facchinetti ${ }^{2}$ \\ ${ }^{1}$ Division of Medical Oncology, University Hospital of Modena, Modena, Italy; ${ }^{2}$ Université Paris-Saclay, Institut Gustave Roussy, Inserm, \\ Biomarqueurs Prédictifs et Nouvelles Stratégies Thérapeutiques en Oncologie, Villejuif, France; ${ }^{3}$ Department of Medicine and Surgery, University \\ of Parma, Parma, Italy; ${ }^{4}$ Medical Oncology Unit, University Hospital of Parma, Parma, Italy; ${ }^{5}$ Department of Oncology, University of Turin at \\ Ordine Mauriziano Hospital, Torino, Italy \\ Contributions: (I) Conception and design: All authors; (II) Administrative support: None; (III) Provision of study materials or patients: None; (IV) \\ Collection and assembly of data: G Guaitoli, M Di Maio, F Facchinetti; (V) Data analysis and interpretation: All authors; (VI) Manuscript writing: \\ All authors; (VII) Final approval of manuscript: All authors. \\ Correspondence to: Francesco Facchinetti, MD, MSc. Université Paris-Saclay, Institut Gustave Roussy, Inserm, Biomarqueurs Prédictifs et Nouvelles \\ Stratégies Thérapeutiques en Oncologie, 114 Rue Edouard Vaillant, 94800 Villejuif, France. Email: francesco.facchinetti@gustaveroussy.fr.
}

Background: Treatment of oncogene-addicted non-small cell lung cancer (NSCLC) has been changed by the advent of tyrosine kinase inhibitors (TKIs). Albeit great benefits are achieved with target therapies, resistance invariably occurs and recourse to alternative treatments is unavoidable. Immune checkpoint inhibitors (ICIs) role and the best setting of immunotherapy administration in oncogene-driven NSCLC are matter of debate.

Methods: We performed a systematic literature review through PubMed, in order to gather all the available information regarding ICI activity and efficacy in oncogene-addicted NSCLC, from both prospective trials and retrospective series. A meta-analysis of objective response rate in different molecular subgroups was provided. Combinatorial strategies including ICIs and related toxicities were also recorded.

Results: Eighty-seven studies were included in the qualitative analysis. EGFR mutation may be a biomarker of poor response to single-agent ICIs (7\% of EGFR-mutant NSCLC patients achieved disease response in prospective trials), while encouraging results have been shown with combination strategies. $K R A S$ mutated disease (response rate, RR, 22\%) has different clinical and pathological characteristics, and the coexistence of additional mutations (e.g., STK11 or TP53) influence tumor microenvironment and response to immunotherapy. Other molecular alterations have been marginally considered prospectively, and data from clinical practice are variegated, given poor effectiveness of ICIs in $A L K$-rearranged disease (RR 9.5\%, pooling the data of retrospective studies) or some encouraging results in $B R A F$-(RR $25 \%$, retrospective data) or MET-driven one (with estimations conditioned by the presence of both exon 14 skipping mutations and gene amplification in reported series).

Conclusions: In oncogene-addicted NSCLC (with the exception of KRAS-mutated), ICIs are usually administered at the failure of other treatment options, but administering single-agent immunotherapy in later disease phases may limit its efficacy. With the progressive administration of TKIs and ICIs in earlystage disease, molecular characterization will become fundamental in this setting.

Keywords: Lung adenocarcinoma; advanced disease; PD-1/PD-L1; adverse events; combination therapies; molecular subgroups

Submitted Aug 13, 2020. Accepted for publication Oct 23, 2020.

doi: $10.21037 /$ tlcr-20-941

View this article at: http://dx.doi.org/10.21037/tlcr-20-941 


\section{Introduction}

The treatment of non-small cell lung cancer (NSCLC) has widely changed in the last decade. In particular, in non-squamous NSCLC, treatment has shifted towards an oncogene-driven approach that has generated significant benefit for patients, globally leading to better survival outcomes, coupled with a good toxicity profile and improved quality of life (1).

The most common driver in NSCLC is represented by mutant $K R A S$, observed in about $25-30 \%$ of patients $(2,3)$. Differently from others targetable alterations, KRAS mutations are usually detected in current/former smokers and, albeit specific inhibitors have been recently proven promising (4), no drugs are approved for clinical use yet. Mutations in the EGFR kinase domain occur in $11-16 \%$ of patients in Western countries, and this rate is higher in the Asian population $(5,6)$. Four to seven percent of patients harbor ALK gene rearrangements and less than $2 \%$ of patients contain alterations of ROS1, BRAF, MET, RET, HER2, NTRK, although relatively rare $(7,8)$. The development and availability of selective agents (TKIs, tyrosine kinase inhibitors) that target these specific alterations has revolutionized the outcomes of patients suffering from oncogene-addicted NSCLC. Despite the major survival improvements generated by the availability of novel-generation inhibitors and new treatment strategies (9), resistance to targeted agents invariably occurs, and this opens many questions about the subsequent therapies in this subgroup of patients.

Alongside chemotherapy, still a valid therapeutic option at the development of resistance to TKIs, immunotherapy represents a pillar in the current management of NSCLC, albeit its role in oncogene-addicted cases (other than $K R A S$-mutant ones) remains debated, as initial evidence is quite discouraging (10). One of the main issues regarding immune checkpoint inhibitors (ICIs) is indeed the identification of patients that are more likely to benefit, and to identify the precise factors predictive of response. On the other hand, one of the major challenges in the continuous care of oncogene-addicted NSCLC is to wisely use all the therapeutic strategies available. In this population, the best setting of immunotherapy administration and the identification of patients suitable for driving benefit from ICIs are not yet defined.

In the present review, we systematically gather all the available evidence concerning activity and efficacy of ICI administration, as single agents or as combinatorial strategies, in oncogene-addicted NSCLC patients. We moreover performed a meta-analysis of objective responses reported with ICIs in differential molecular subgroups of NSCLC. A significant amount evidence has already been published dealing with immunotherapy role in oncogeneaddicted NSCLC. Nevertheless, the goal of the present work is to present all the data, driven both from prospective studies and retrospective series, approaching independently every single molecular entity (e.g., EGFR and KRAS mutations, $A L K$ rearrangements and other "rare" NSCLC activating alterations). We aim indeed to provide treating physicians with a complete view of the clinical data on this topic. We present the following article in accordance with the PRISMA reporting checklist (available at http://dx.doi. org/10.21037/tlcr-20-941).

\section{Methods}

\section{Search strategy and selection criteria}

The review was performed according to Preferred Reporting Items for Systematic Reviews and Meta-Analyses guidelines. The search was conducted in accordance with the principles outlined in the Cochrane Handbook for Systematic Reviews of Interventions. The database searched was MEDLINE (data cutoff of March $1^{\text {st }}, 2020$ ). The search items were "(lung neoplasms OR lung cancer, OR carcinoma[MeSH Terms]) AND (checkpoint inhibitors OR check-point inhibitors OR PD-1 OR PD-L1 OR nivolumab OR pembrolizumab OR atezolizumab OR durvalumab OR avelumab) AND (EGFR OR ALK OR ROS1 OR BRAF OR MET OR KRAS OR MET OR oncogene addicted)"; "(nivolumab OR pembrolizumab OR atezolizumab OR immune checkpoint inhibitor) AND non-small cell lung cancer"; "(lung neoplasms OR lung cancer, OR carcinoma [MeSH Terms]) AND (checkpoint inhibitors OR checkpoint inhibitors OR PD-1 OR PD-L1 OR nivolumab OR pembrolizumab OR atezolizumab OR durvalumab OR avelumab)" (only clinical trials were selected in the search of this latter item.).

We aimed to collect all evidence concerning activity and efficacy of ICI in oncogene-addicted NSCLC populations. Assuming that these patients do not harbor a differential risk of ICI-dependent adverse events compared to patients lacking a molecular driver, we did not address toxicities issues regarding ICI monotherapy or combinations with treatments (e.g., chemotherapies) that have been evaluated in larger populations, regardless of mutational status. On 
the contrary, as combinatorial strategies involving targeted agents and ICI represent a prerogative of oncogeneaddicted cases, data regarding adverse events of these treatments were collected.

Inclusion criteria for studies to be included in the qualitative and quantitative synthesis were represented by the presence of at least one measure of activity [i.e., response and disease control rates, progression-free survival (PFS) and/or efficacy [overall survival (OS)]. Exclusion criteria were: articles not written in English, reviews, commentaries, opinions, case reports, studies gathering the outcomes of different oncogene-addicted patients (e.g., EGFR-mutated and $A L K$-rearranged ones versus wild-type ones), not relevant articles. Case reports usually describe the positive outcomes of ICI administration in peculiar situations, suggesting an intrinsic publication bias, potentially leading to overestimate the real benefit in the specific oncogenedriven population. In the same way, case series were considered only if consecutive patients were included, meaning that no selection bias had been performed. As we are dealing with different oncogene-addicted entities, only studies reporting the outcomes of single oncogene-addicted populations were considered. Studies reporting outcomes of oncogene-addicted NSCLC populations, but lacking patients' number, were excluded, as well as translationalbiomarker studies including patients enrolled in clinical trials, whose outcomes had been reported in these latter. Concerning different publications presenting data from the same clinical trial, the reports including the outcomes of oncogene-addicted patients and the ones with the longest follow-up were prioritized. We encountered studies that only reported the statistical differences (e.g., hazard ratios, HR, p values) between two oncogene-addicted entities (e.g., EGFR-mutated versus wild-type population), lacking a numerical value describing the outcomes measures (e.g., median progression-free survival, PFS, or overall survival, OS). When we faced these studies, only prospective clinical trials were included. Only the studies, prospective and retrospective, that clearly reported the objective responses and the number of treated patients were included in the meta-analysis.

\section{Data extraction and risk of bias assessment}

Two reviewers (Giorgia Guaitoli and Francesco Facchinetti) independently screened titles and abstracts of all identified references. Full-text documents of reports of potential interest were independently assessed by the two reviewers to determine whether they met the predefined inclusion criteria. Any disagreements were solved by consensus or arbitration by a third person (Marcello Tiseo). A data extraction form was developed specifically for the purpose of this assessment to collect information on patient characteristics, type of treatments, and outcome measures.

\section{Data synthesis and analysis}

Descriptive statistics were used to summarize characteristics data of patients and tumors. The main results were summed in a table and a quantitative synthesis was planned for all the reported cases.

A narrative synthesis was provided instead of statistical analysis with regard to efficacy outcomes (PFS, OS). Metaanalysis on objective response rate was performed with MedCalc Statistical Software version 19.4.1 (MedCalc Software Ltd, Ostend, Belgium; https://www. medcalc. org; 2020). Meta-analysis was performed separately (I) for prospective trials and (II) for retrospective studies. The software uses a Freeman-Tukey transformation (arcsine square root transformation) to calculate the weighted summary proportion under the fixed and random effects model. Heterogeneity is measured by Cochran's Q, calculated as the weighted sum of squared differences between individual study proportion and the pooled proportion across studies. Q is distributed as a chi-square statistic with $\mathrm{k}$ (number of studies) minus 1 degrees of freedom. When the number of included studies is small, Q has low power to test heterogeneity, whilst $\mathrm{Q}$ has too much power if the number of studies is large. The $\mathrm{I}^{2}$ statistic describes the percentage of variation across studies that is due to heterogeneity rather than chance. $\mathrm{I}^{2}=100 \% \times(\mathrm{Q}-$ $\mathrm{df} / \mathrm{Q}$. Unlike Q it does not inherently depend upon the number of studies considered.

\section{Results}

\section{Results of the systematic search}

Our search strategies in MEDLINE identified a total of 3,322 titles (Figure 1). In total, 2,716 of them were excluded as not pertinent to our review. Of the 606 remaining studies, 105 were considered duplicates. Five hundred and one fulltexts were then evaluated. Among them, 407 study were excluded ( $n=367$ not containing data of interest; $n=28$ case reports; $n=12$ not written in English). Ninety-four study were therefore included in the final analysis and we add 


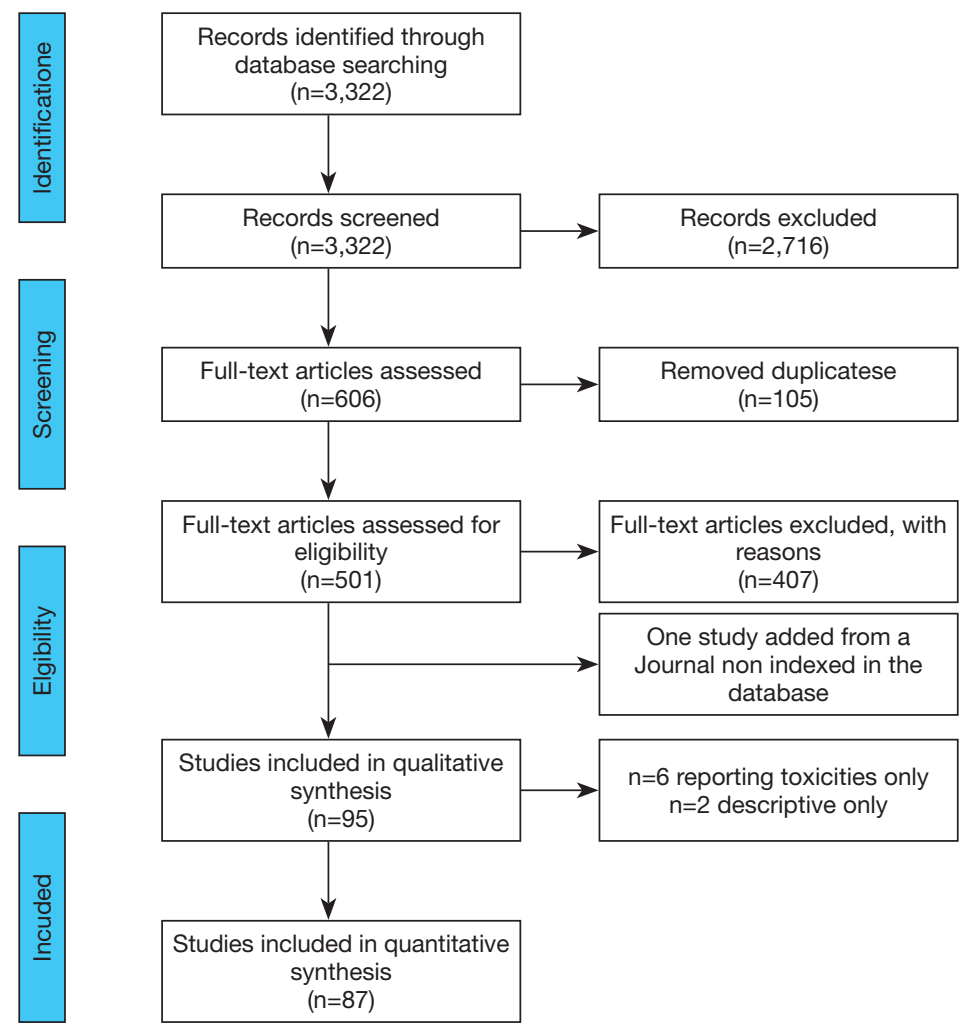

Figure 1 PRISMA flow diagram depicting the systematic review process leading to the identification of studies included in the systematic review.

one title (11), whose Journal is not MEDLINE indexed, as Authors were aware of its relevance for the topic. Six studies only reported toxicities issues due to combination of targeted with immunotherapy agents and two studies were considered only as descriptive (i.e., no specific data of a peculiar subset of oncogene-addicted patients was reported). Eighty-seven studies were therefore included in the qualitative analysis: 34 contain prospective data from clinical trials, whereas 53 report the outcomes of oncogene-addicted NSCLC patients as retrospective series/registries. With regard to prospective clinical studies, the ICI evaluated (as monotherapy or within combinatorial strategies) has always been reported. Concerning retrospective data, the large majority of studies reported outcomes from single-agent anti-PD-1/ PD-L1 treatments (especially nivolumab), while a minority of patients had been exposed to combinations involving antiCTLA-4 agents.

\section{EGFR-driven NSCLC and ICIs}

Non-smokers patients globally derive inferior benefit from
ICIs $(12,13)$, and patients with oncogene aberrations (with the exception of $K R A S$ ) have a negligible tobacco exposure; they may indeed have less somatic mutations (recapitulated by tumor mutation burden, TMB) and lower tumor immunogenicity (14-16). Of note, EGFR-driven diseases have a low co-localization of PD-L1 tumor cells and CD8+ TILs (tumor infiltrating lymphocytes), especially if compared with KRAS-mutant NSCLC (17-21). A positive effect of TKIs administration on these parameters, measured compared biopsies obtained at baseline at resistance, proposed by Isomoto and colleagues (22), had not been registered in a previous work by Gainor and collaborators (17). Then the hypothesis that the lack of an inflammatory microenvironment and the lower concurrent expression of PD-L1 and TILs may support immune-resistance in these tumors (17). Nevertheless, in functional in vitro studies, mutant EGFR has been showed to up-regulate PD-L1 trough intracellular signaling, thus suggesting the co-existence of the two targets may provide a potential molecular background for ICI activity $(23,24)$. 
Table 1 Data about EGFR-positive patients in phase 2 or 3 clinical trials comparing immune checkpoint inhibitors with chemotherapy

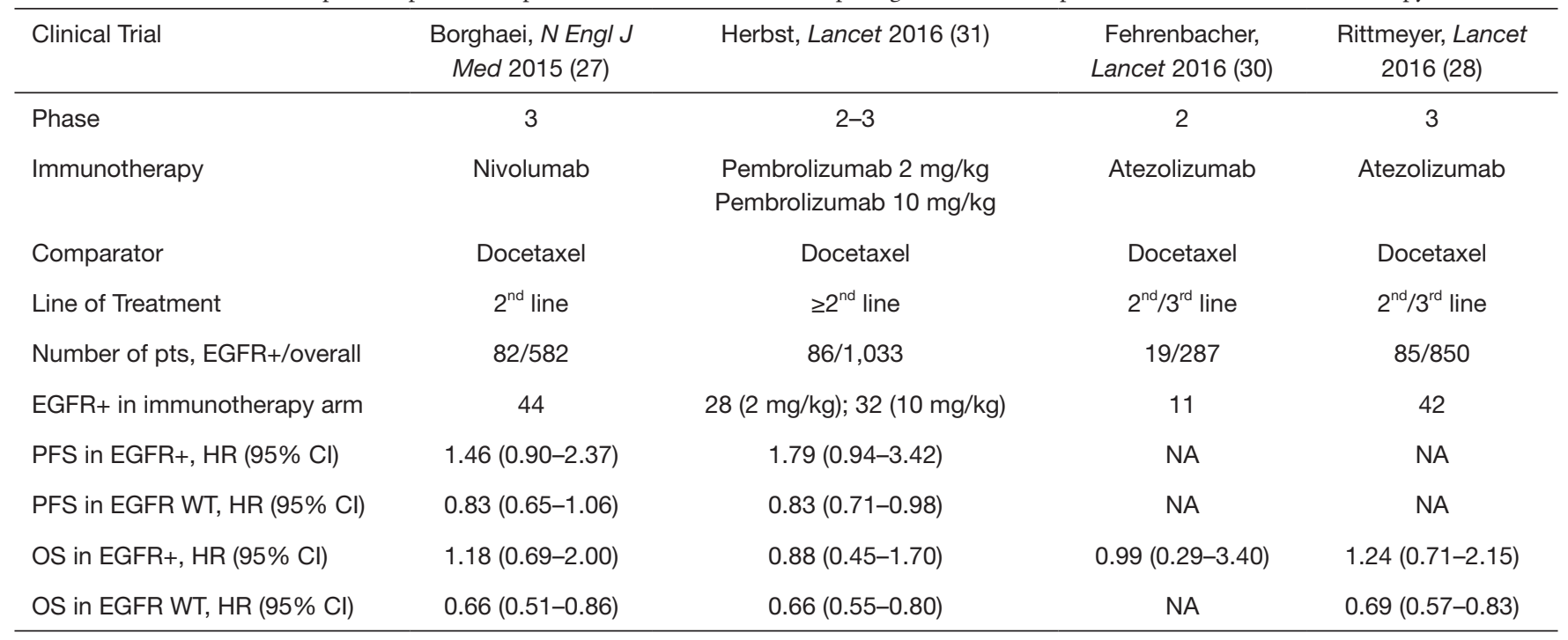

Pts, patients; EGFR+, EGFR positive; WT, wild-type; OS, overall survival; PFS, progression free survival; $\mathrm{HR}$, hazard ratio; Cl, confidence interval; NA, not available.

\section{Data from clinical trials with single-agent anti-PD-1/ PD-L1}

EGFR-mutated NSCLC is the oncogene-addicted subgroup most represented in clinical trials with immunotherapy, that appears to be poorly effective in this population. Indeed, even if some responses are reported, and some of them are protracted $(25,26)$, is a long-term benefit in PFS and OS is generally lacking, especially if compared with the wild-type (WT) population.

In particular, results of phase 2 and 3 trials of second line immunotherapy compared with docetaxel, suggest that ICIs do not add any advantage over chemotherapy in this subgroup of patients (27-31). In the OAK trial, second line atezolizumab improved OS in all predefined subgroups, with the exception of $E G F R$-mutated patients [HR 1.24; 95\% confidence interval (95\% CI): 0.71-2.18 versus $0.69 ; 95 \%$ CI: $0.57-0.83$ in the EGFR WT) and this was confirmed also in the Japanese population $(28,32)$. Consistently, still with the limitation of subgroup analyses, also nivolumab and pembrolizumab failed in outperforming docetaxel in this setting $(27,31)$ (Table 1).

Nevertheless, in all phase 3 studies, EGFR-mutated patients were a low percentage of the overall population (between $6 \%$ and $14 \%$ ), precluding the identification of a subgroup of patients more likely to benefit from immunotherapy (e.g., according to PD-L1 status or type of mutation).
In phase 1 or 2 trials (Table 2) (33-41), conflicting ORRs are reported, including the absence of response (37-39) or some prolonged responses, as in CA209-003 (26). This study enrolled 13 EGFR-mutated patients and two of them were still alive at 5 -years follow-up: one harboring an exon 20 insertion (pretreated with erlotinib), and one harboring an exon 18 missense mutation (TKI-naïve) (26).

Albeit responses occur regardless of mutational status, ORRs are usually lower in mutant patients than in those WT status $(34,40)$. When pooling activity data in the metaanalysis indeed, ORR was 7.2\% (95\% CI: 3.7-11.6) and $21.3 \%$ (95\% CI: $17.9-24.9)$ in the EGFR-mutant ( $\mathrm{n}=187)$ and in the EGFR-WT (n=1264) populations, respectively (Figure 2, Tables S1,S2). Heterogeneity among studies was low $\left(\mathrm{I}^{2}=10.2 \%\right)$ for $E G F R$-mutant and moderate $\left(\mathrm{I}^{2}=47.7 \%\right)$ for $E G F R-W T$. The absence of previous or current smoking attitude, that usually characterize EGFR-positive patients, may play a role in the poor responses reported.

The chance of obtaining an objective response was significantly lower in EGFR-mutant patients compared to EGFR-WT [odds ratio (OR) $0.33,95 \%$ confidence interval $0.19-0.59, \mathrm{P}=0.002]$, without significant heterogeneity among studies.

Even in setting different from advanced disease, immunotherapy does not seem to improve outcomes, again with the limitation of subgroups. In the PACIFIC trial in stage III NSCLC, durvalumab after chemo-radiotherapy, 


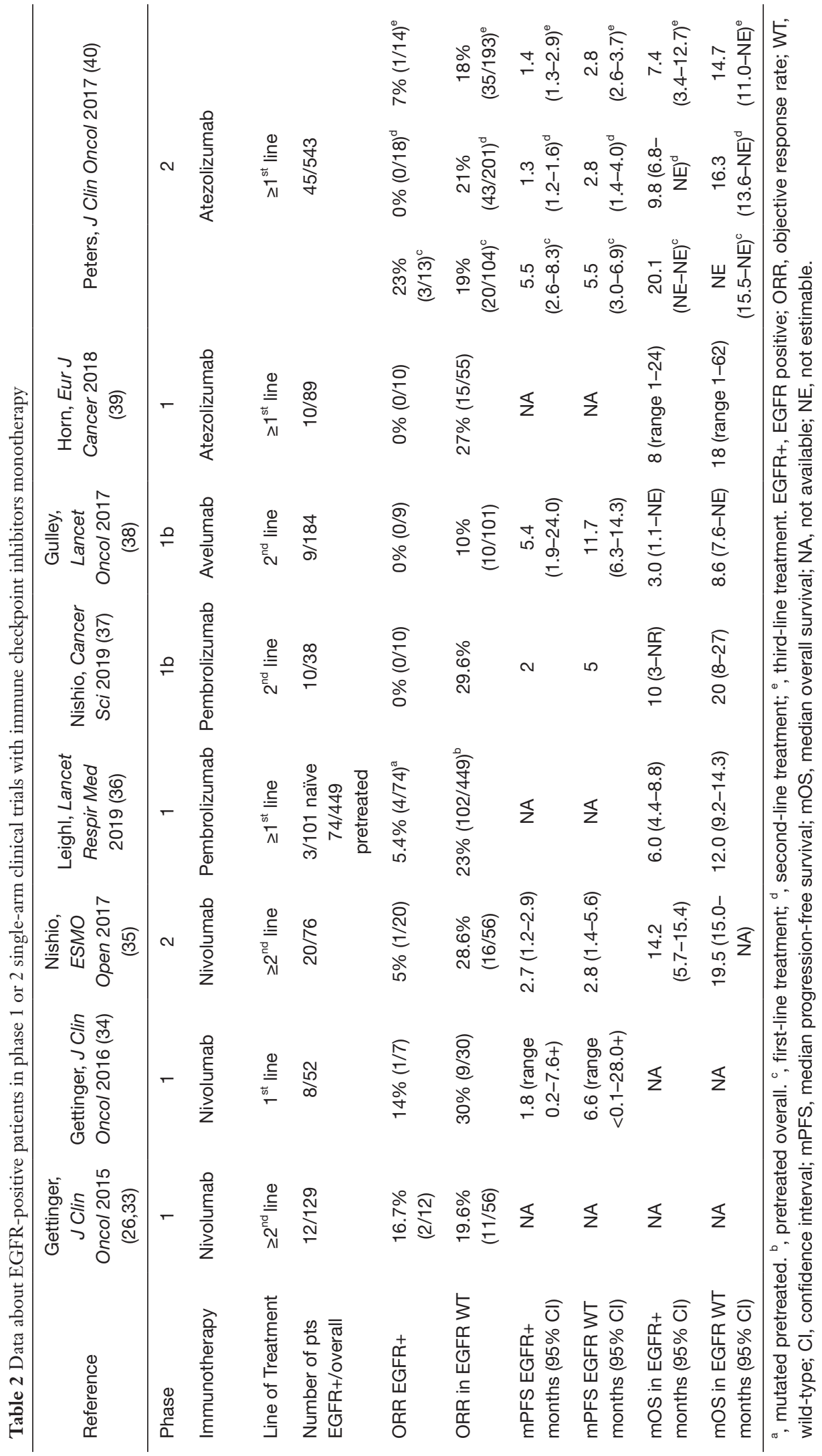


EGFR-mut, single agent, prospective trials

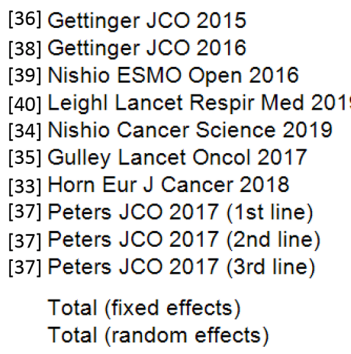

Total (random effects)

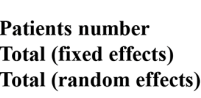

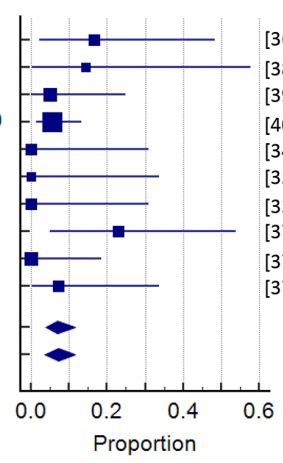

187

7.015\% (95\% CI 3.871-11.526) $7.158 \%$ (95\% CI 3.711-11.618)
EGFR-wild type, single agent, prospective trials

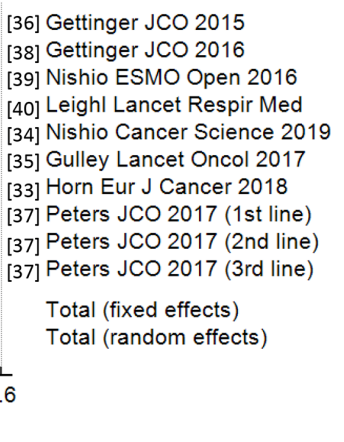

Patients number Total (fixed effects) Total (random effects)

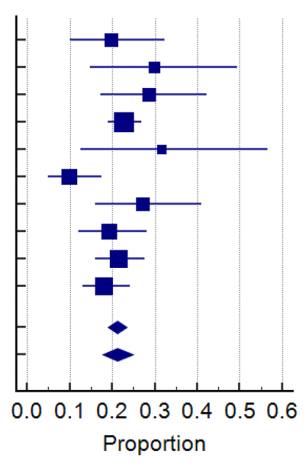

1264

$21.145 \%$ (95\% CI 18.932-23.492) $21.277 \%$ (95\% CI $17.883-24.881)$

Figure 2 Meta-analysis of objective responses according to EGFR status in prospective trials of single-agent immune checkpoint inhibitors.

significantly improved PFS and OS in the global population and in a wide range of subgroups, while the benefit for EGFR-positive patients ( $\mathrm{n}=45)$ is at least uncertain (HR for PFS 0.76; 95\% CI: 0.35-1.64) (42,43).

\section{Real-life experiences with single-agent anti-PD-1/PD- L1}

Moving to real-life data, the evidence of ICIs effectiveness in the EGFR-mutated population mainly derives from retrospective cohorts of pretreated patients (Tables 3,4).

In studies comparing the outcomes of EGFR-mutated NSCLC with the WT counterpart (Table 3), the activity of ICIs and their impact on survival estimations appear almost invariably disappointing in the first group of patients. Similarly to what observed for the prospective trials, pooling the results of retrospective experiences, ORR in EGFR-mutant $(\mathrm{n}=1,069)$ and EGFR-WT $(\mathrm{n}=2,212)$ subgroups were $11.1 \%$ (95\% CI: 9.3-13.0) and 25.7\% (95\% CI: 20.6-31.1), respectively (Tables S3,S4). There was no evidence of heterogeneity $\left(\mathrm{I}^{2}=0 \%\right)$ among proportions in EGFR-mutant, and evidence of significant heterogeneity ( $\mathrm{I}^{2}$ $=75.5 \%$ ) among proportions in EGFR-WT.

In the subgroup analysis of nivolumab expanded access program reported by Garassino and colleagues, $90 \%$ of the patients had previously received EGFR-TKIs and all but one had been exposed to at least a chemotherapy regimen (44). Of interest, the benefits driven from nivolumab were differential according to smoking status. Out of the 51 never-smokers, EGFR-mutated patients, disease response and stability were recorded in one and 10 cases, respectively, with a median PFS of 2 months and a median OS of 5.6 months.
On the other hand, among the 34 EGFR-positive cases, either current or former smokers, responses and stabilities were observed in seven and nine cases respectively, with a median PFS and OS of 4 and 14.1 months, respectively (44). Given the questionable role of median estimation of survival in evaluating immunotherapy effectiveness $(17,82), 6$-months PFS, 12-months PFS and 12-months OS resulted 9.8\% and $36.4 \%, 4.9 \%$ and $30.3 \%, 37.8 \%$ and $55.6 \%$ in the two respective groups. Irrespective of smoking status, Mazières and colleagues reported a 6-month and a 12-month PFS rates of $18 \%$ and $6 \%$ for EGFR-positive patients exposed to ICIs (68). In a previous report, Yoshida and collaborators suggested that smoking exposure, duration of previous EGFR-TKI therapy and type of EGFR mutation had an impact on nivolumab PFS (63). Similar impact of the type of EGFR mutation on ICIs outcomes has been reported in two additional large series, as in both cases $E G F R^{\mathrm{L} 858 \mathrm{R}}$ patients experienced better outcomes compared to $\mathrm{EGFR}^{\text {del19 }}$ ones $(68,69)$. Facing a lack of definite conclusion on the role of PD-L1 expression for the prediction of ICIs benefit in EGFR-driven diseases $(68,69)$, nivolumab activity has been suggested to be correlated with CD8+ TILs density (64). Dealing with long-term survivorship provided by ICI (83), no patients among the 42 oncogene-addicted ones (39 EGFR-positive, three $A L K$-rearranged), experienced a survival longer than three years in the study provided by Hu-Lieskovan and colleagues (84).

\section{Combinatorial strategies}

To achieve better response or delay/overcome resistance, combination strategies with different ICIs, or with ICIs 
Table 3 Comparison between EGFR mutated and wild-type patients receiving immune checkpoint inhibitors in single cohorts

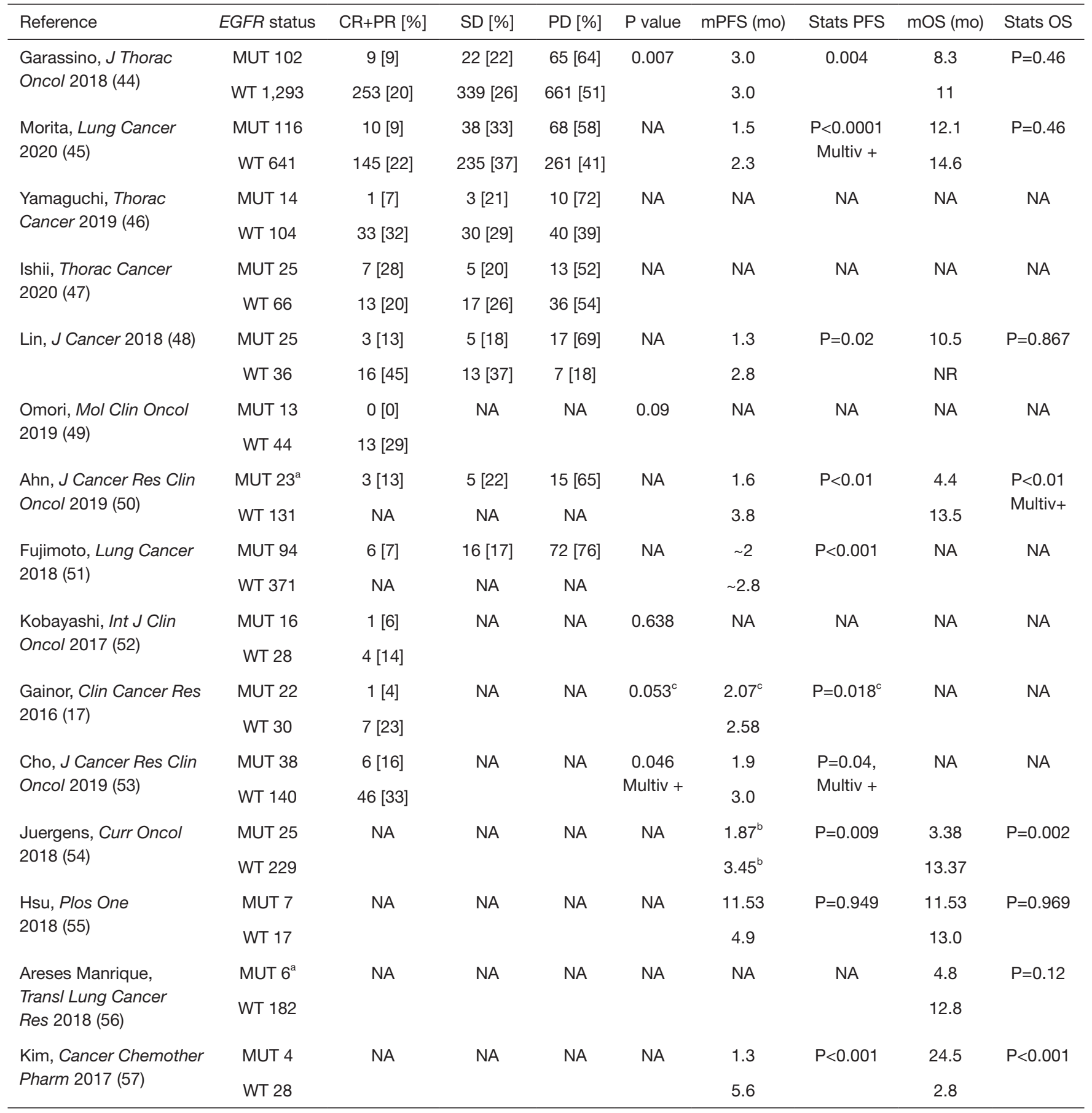

${ }^{a}$, including $1 \mathrm{ALK}+$ pt. $^{\mathrm{b}}$, time-to-treatment discontinuation. ${ }^{\mathrm{c}}$, if considering also the six non-responding ALK+ patients in the group of EGFR-mutated. MUT, mutated; WT, wild-type; CR, complete responses; PR, partial responses; SD, stable diseases; PD, progressive diseases; NA, not available; Multiv +, positive association at the multivariate analysis; mPFS, median progression-free survival; mo, months; Stats, statistics; mOS, median overall survival. 
Table 4 Studies reporting the outcomes of EGFR-mutated patients receiving immune checkpoint inhibitors

\begin{tabular}{|c|c|c|c|c|c|c|}
\hline Reference & Patients EGFR+ & $\mathrm{CR}+\mathrm{PR}[\%]$ & SD [\%] & $\mathrm{PD}[\%]$ & mPFS (mo) & mOS (mo) \\
\hline Sakamoto, Mol Clin Oncol 2019 (59) & $24^{a}$ & $4[17]$ & $4[17]$ & 15 [63] & 2.00 & NA \\
\hline Sato, Plos One 2019 (60) & 9 & $1[11]$ & $0[0]$ & $7[78]$ & 1.00 & $\mathrm{NR}^{\mathrm{c}}$ \\
\hline Ng, Cancer 2019 (61) & 12 & $0[0]$ & $2[17]$ & 10 [83] & 1.43 & NA \\
\hline Yoshida, Ann Oncol 2018 (63) & 24 & $2[8]$ & $4[17]$ & 18 [75] & NA & NA \\
\hline Haratani, Ann Oncol 2017 (64) & 25 & $5[20]$ & $4[16]$ & 16 [64] & 1.5 & NA \\
\hline Yamada, Cancer Med 2019 (65) & 27 & $6[22]$ & 5 [19] & $13[48]$ & $57.5 \mathrm{~d}$ & $76.5 \mathrm{~d}$ \\
\hline Song, Sci Rep 2019 (66) & 3 & $1[33]$ & $2[67]$ & $0[0]$ & NA & NA \\
\hline Hastings, Ann Oncol 2019 (69) & 171 & $17[10]$ & $34[20]$ & $113[66]$ & 1.8 & 9.4 \\
\hline Guibert, Lung Cancer 2019 (70) & 5 & $0[0]$ & $0[0]$ & $5[100]$ & NA & NA \\
\hline de Vries, Ann Oncol 2019 (71) & 5 & \multicolumn{2}{|l|}{$2[40]$} & $3[60]$ & NA & NA \\
\hline Oya, Oncotarget 2017 (72) & 22 & 2 [9] & NA & NA & 1.9 & 8.4 \\
\hline Schouten, Lung Cancer 2018 (73) & 9 & $0[0]$ & NA & NA & NA & NA \\
\hline Bagley, Lung Cancer 2017 (74) & 12 & $1[8]$ & NA & NA & NA & NA \\
\hline Rizvi, J Clin Oncol 2018 (75) & 17 & \multicolumn{2}{|c|}{$1 \mathrm{R}$ or $\mathrm{SD}>6 \mathrm{mo}[7]$} & NA & NA & NA \\
\hline Costantini, Lung Cancer 2019 (76) & 10 & \multicolumn{2}{|c|}{9 no early PD [90] } & 1 early PD [10] & NA & NA \\
\hline \multirow[t]{2}{*}{ Landi, J Immunother Cancer 2019 (80) } & 47 Bone mets+ & $1[2] \quad P=0.03$ & NA & NA & $2.0 \quad P=0.14$ & $P=0.04$ \\
\hline & 55 Bone mets - & $8[14]$ & NA & NA & 3.0 & 12.8 \\
\hline \multirow[t]{2}{*}{ Gainor, Ann Oncol 2020 (81) PD-L1 $\geq 50 \%$} & $\begin{array}{c}13 \text { never-light } \\
\text { smokers }\end{array}$ & $3[23]$ & NA & NA & NA & NA \\
\hline & 4 heavy smokers & $0[0]$ & & & & \\
\hline
\end{tabular}

${ }^{\mathrm{a}}$, including one rearranged each for $A L K, R O S 1, R E T .{ }^{\mathrm{b}}$, including one KRAS+ and one ROS1+. ${ }^{\mathrm{c}}$, only one patient had received EGFRTKI before nivolumab. ', all cases with PD-L1 TPS >50\%. EGFR+, EGFR-mutated; CR, complete responses; PR, partial responses; SD, stable diseases; PD, progressive diseases; NA, not available; mPFS, median progression-free survival; mo, months; mOS, median overall survival; d, Days; mets, metastases.

and chemotherapy or target therapies have been designed (85-90) (Table 5).

To date, Impower 150 is the only phase 3 trial with consistent results regarding $E G F R$-mutated patients, showing an improvement in both PFS and OS with the combination of atezolizumab + bevacizumab + carboplatin + paclitaxel $(85,92)$. Survival benefit was obtained despite a lower PD-L1 positivity rate in the mutated population 
Table 5 Phase 1-3 clinical trials about combination strategies including EGFR- and/or KRAS-mutated patients

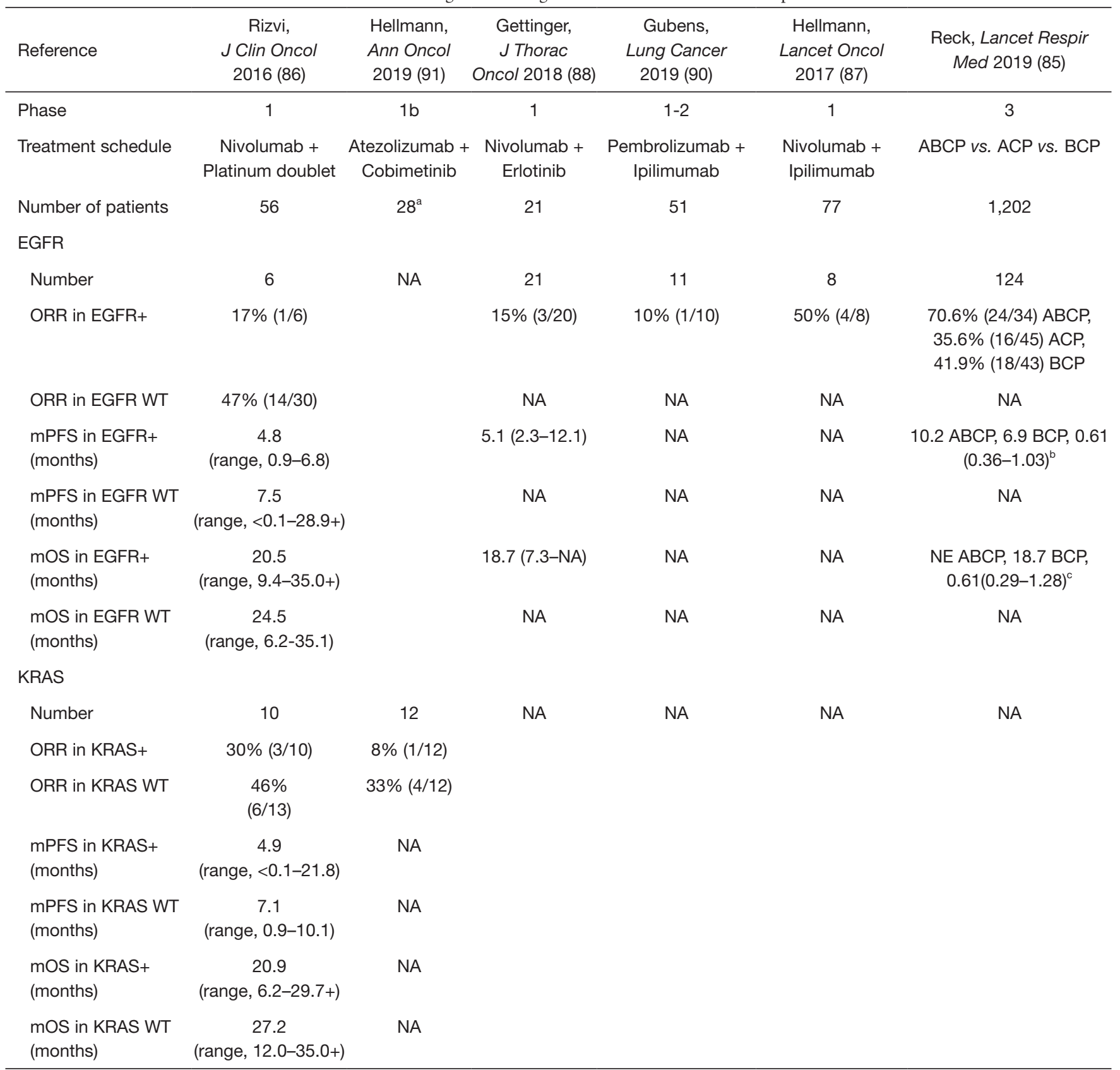

a, 28 NSCLC pts of 152 pts overall. ${ }^{b}$, With EGFR sensitising mutation: 10.3 vs. 6.1 mo, HR 0.41 (95\% Cl: 0.23-0.75). ' , With EGFR sensitising mutation: NE vs. $17.5 \mathrm{mo}$, HR 0.31 (95\% Cl: 0.11-0.83). ORR, objective response rate; mPFS, median progression-free survival; mOS, median overall survival; HR, hazard ratio; $\mathrm{Cl}$, confidence interval; $\mathrm{ABCP}$, atezolizumab + bevacizumab + paclitaxel + carboplatin; ACP, atezolizumab + paclitaxel + carboplatin; BCP, bevacizumab + paclitaxel + carboplatin; NA, not available.

compared with the WT one, suggesting that chemotherapy and bevacizumab may enhance immunotherapy activity, favoring neoantigen release or T-cell tumor infiltration (85). In particular, benefits were obtained with the addition of both immunotherapy and anti-angiogenic agent to platinum-based chemotherapy: this combination significantly improved ORR, PFS and OS when compared with bevacizumab + chemotherapy (while a formal comparison with immunotherapy + chemotherapy was not reported). In the EGFR-positive subgroup $(n=124)$, the 
addition of atezolizumab prolonged mPFS: 10.2 months (95\% CI: 7.9-15.2) vs. 6.9 (95\% CI: 5.7-8.5); HR 0.61 (95\% CI: 0.14-1.07). Additionally, overall survival was not estimable (95\% CI: 17.0-NE) vs. 18.7 months (13.4-NE); HR 0.61 (95\% CI: 0.29-1.28). Moreover, when selecting for common, sensitizing mutations (exon 19 deletion and L858R mutation, $\mathrm{n}=61$ ), OS HR 0.31 (95\% CI: 0.11-0.83) was reported (Table 5) (85).

In the phase 1 trial of pembrolizumab + ramucirumab, one EGFR-positive patient, previously treated with erlotinib, experienced stable disease as best response, and discontinued treatment after nine cycles (93). With the combination of nivolumab plus chemotherapy responses were obtained regardless of EGFR or KRAS status, with 1 -year OS rates similar between oncogene-addicted and WT subgroups, still with shorter mOS and mPFS in the mutated subgroups (86).

The phase 1 trial Checkmate-012 was specifically designed for an EGFR-mutant population and enrolled chemotherapy-naïve patients to receive a combination of nivolumab plus erlotinib. Of the 21 patients included, 20 were already pretreated with erlotinib, in all cases discontinued due to disease progression. Responses were achieved in three cases (ORR 15\%) including one complete response (CR) (88). mOS and mPFS were 18.1 and 5.1 months respectively, numerically longer in smoker patients than in non-smoker patients. ORR was higher in $\mathrm{PD}-\mathrm{L} 1 \geq 1 \%$. The single TKI-naïve patient enrolled, achieved a CR (the patient harbor L858R + S768I mutation, with PD-L1 65\%) (88).

In a post-hoc analysis of the phase 1 trial combining nivolumab plus ALT-803 (IL-15 superagonist), two patients with PD-L1 expression included between $1 \%$ and $50 \%$ experienced stable disease, and one of them was an EGFRmutated patient harboring exon 20 mutation, treated with the combination for 17 months (94). In CA209-003, a patient harboring exon 20 mutation achieved durable benefit with immunotherapy, and indeed this may be relevant considering that this type of mutation correlates with resistance to clinically available TKIs and poor prognosis $(95,96)$.

\section{Toxicity issues in TKI-ICI combinations and sequential treatments \\ Evidence from clinical trials}

In almost all immunotherapy trials that allowed EGFRmutated patients inclusion, their enrollment was permitted at the failure of a previous line with TKI. If this strategy did not show particular efficacy, it did not raise relevant toxicities issues, while the reverse strategy (immunotherapy followed by target therapy) or the combination of ICIs + TKI appear to be dangerous in some experiences $(89,97)$. The phase 2 trial of first line pembrolizumab in EGFRmutated patients ceased prematurely for futility: indeed, of 10 patients no-one achieved a response (89). What is even more interesting, is that in seven patients treated with second line erlotinib, $86 \%$ experienced a treatment-related adverse event.

A rate of interstitial lung disease (ILD) higher than expected has been reported in TATTON trial (97). Despite $43 \%$ ORR, all patients treated with durvalumab plus osimertinib discontinued treatment. The most common adverse events (AEs) were rash, vomiting and diarrhea, but the $22 \%$ rate of ILD was high enough to cause the early recruitment termination in the phase 3 CAURAL trial (98).

According to phase 1 trials preliminary results, combinations of immunotherapy plus a first generation TKI seem more tolerable $(88,99,100)$.

\section{Evidence from clinical practice}

The toxicity alerts emerging from the sequential administration of ICIs and EGFR-TKIs have also been reported in clinical practice. If treatment with EGFR-TKIs followed by ICIs seems to be safe $(101,102)$, the inverse sequence can be accompanied by a remarkable proportion of AEs, suggesting a putative role of ICIs in "priming" the toxicity exerted by EGFR-TKIs. Severe immunerelated AEs (mainly ILD) occurred in six out of 41 patients receiving osimertinib after ICIs and were more common among patients initiating osimertinib within three months since ICIs last dose (101). Any-grade ILD was reported in 18 out of 70 patients $(26 \%)$ of patients receiving the sequence of nivolumab and EGFR-TKIs (103) and a similar proportion was reported in an additional smaller series of 26 patients (102). Grade 3-4 liver toxicity occurred in four out of seven patients receiving the sequential treatment with nivolumab and osimertinib (104). Takenaka and colleagues reported the case of a patient experiencing colitis while receiving nivolumab; after its resolution, colitis was reexacerbated by osimertinib administration (105). Globally, compared to first- and second-generation EGFR-TKIs, osimertinib appears to retain the higher risk of inducing immune-related AEs (irAEs) when administered after ICIs $(101,102)$.

According to the current guidelines nevertheless $(106,107)$, the administration of ICIs before EGFR-TKI should be exceptional (e.g., in the case of an EGFR mutation 
status unknown at the beginning of ICI, subsequently turning out positive), given the opposite levels of activity and efficacy in favor of targeted agents. The standard of care is incorporating chemotherapy + bevacizumab + atezolizumab in the treatment of EGFR-mutated patients after all the targeted treatment options. No alerts concerning irAEs emerged in Impower150 trial with regard to patients having previously received EGFR-TKIs (85), and the lack of relevant AEs in the case of the sequence encompassing EGFR-TKI followed by ICIs is reassuring in this sense. On the other hand, attention should be addressed to locally-advanced NSCLC patients treated with chemo-radiotherapy followed by durvalumab (43) regardless of mutational status, who then progress on or after anti-PD-L1 therapy completion and undergo EGFRTKI treatment due to the detection of EGFR mutation.

\section{KRAS-driven NSCLC and ICIs}

Especially when compared with other oncogene-driven tumors, the immune context characterizing $K R A S$-mutant diseases appear more prone to ICIs activity. Higher PDL1 expression (both by tumor and immune cells), increased TILs density and TMB, that usually characterize KRASmutated patients, are likely a consequence of their smoking habits, differently from other molecular alterations $(14,17,21,108-110)$.

\section{Perspective evidences, real-life experiences and combinatorial strategies}

Albeit responses are reported, results in KRAS-mutated patients are not uniform and it remains difficult to draw strong conclusions.

In the Checkmate 057 trial, nivolumab performed even better in KRAS-positive patients than in KRAS WT population (HR for OS 0.52, 95\% CI: 0.29-0.95) (27), while with atezolizumab OS was similar between KRASmutated and KRAS WT or unknown patients $(28,111)$. In the phase $2 \mathrm{BIRCH}$ trial with atezolizumab, $28 \%$ of patients $(\mathrm{n}=137)$ were $K R A S$-mutated and objective responses have been reported regardless of KRAS status, with higher rates and a trend for prolonged $\mathrm{mOS}$ and $\mathrm{mPFS}$ in second-line treatment (cohort 2) (40). On the contrary, phase 1 experiences with avelumab and atezolizumab report numerically lower ORR in mutated patients than in wildtype, with shorter mOS $(38,39)$, while first-line nivolumab performed better in KRAS-mutated patients in terms of ORRs and mPFS (34) (Table 6). In the meta-analysis of prospective trials, $21.9 \%$ (95\% CI: $14.0-30.9$ ) and $17.4 \%$ (95\% CI: $11.3-24.5)$ of KRAS-mutant $(\mathrm{n}=198)$ and KRASWT $(\mathrm{n}=452)$ patients experienced disease response, respectively (Figure 3, Tables S5,S6), with moderate but non statistically heterogeneity among studies $\left(\mathrm{I}^{2}=50.7 \%\right)$ in $K R A S$-mutant and statistically significant heterogeneity among studies $\left(\mathrm{I}^{2}=64.8 \%\right)$ in $K R A S$-WT.

When compared within a random-effects model, the chance of obtaining an objective response was not significantly different between $K R A S$-mutant patients and KRAS-WT patients (OR 1.54, 95\% CI: 0.81-2.92, $\mathrm{P}=0.19$ ), without significant heterogeneity among studies.

The activity and efficacy of the combination of platinumpemetrexed chemotherapy with pembrolizumab, the new standard of care for the first-line treatment in nonsquamous NSCLC lacking EGFR and $A L K$ abnormalities (especially in the case of PD-L1 TPS $<50 \%$ ), have been validated regardless of $K R A S$ status (110).

Albeit rarely showed as significantly conditioning better activity and effectiveness of ICIs compared to KRAS-WT cases in real-life studies, the presence of KRAS mutations can globally be interpreted as a potential marker of benefit to immunotherapy in lung cancer patients (Table 7). With the intrinsic limitation due to the retrospective nature of the majority of the studies, disease control was observed in approximately $50 \%$ of patients. In the meta-analysis, $26.7 \%$ (95\% CI: 20.5-33.4) out of 811 KRAS-mutated and $22.4 \%$ (95\% CI: $13.3-33.0)$ out of 529 KRAS-WT NSCLC experienced disease response (Tables S7,S8), with statistically significant heterogeneity in both series $\left(\mathrm{I}^{2}=\right.$ $70.8 \%$ and $80.4 \%$, respectively).

In the study provided by Mazieres and collaborators, out of 271 KRAS-mutated patients receiving ICIs, 38\% and $26 \%$ were reported as progression-free at six and 12 months, respectively (68). In the series including the largest number of KRAS-mutated NSCLC, median OS was always longer than one year from ICIs initiation $(68,112,114)$, a relevant result in this population of pretreated patients.

Combination strategies, that may be appealing in this setting, are in the preliminary phase of development. The phase 1 trial about the combination of nivolumab plus chemotherapy included $10 \mathrm{KRAS}$-mutated patients that, despite shorter mPFS and mOS, showed 1-year OS rates similar to WT ones (90\% vs. 100\%). For the combination of pembrolizumab plus epacadostat (IDO1 inhibitor), five responses were reported, including two $K R A S$-mutated patients (118) and with atezolizumab plus cobimetinib 


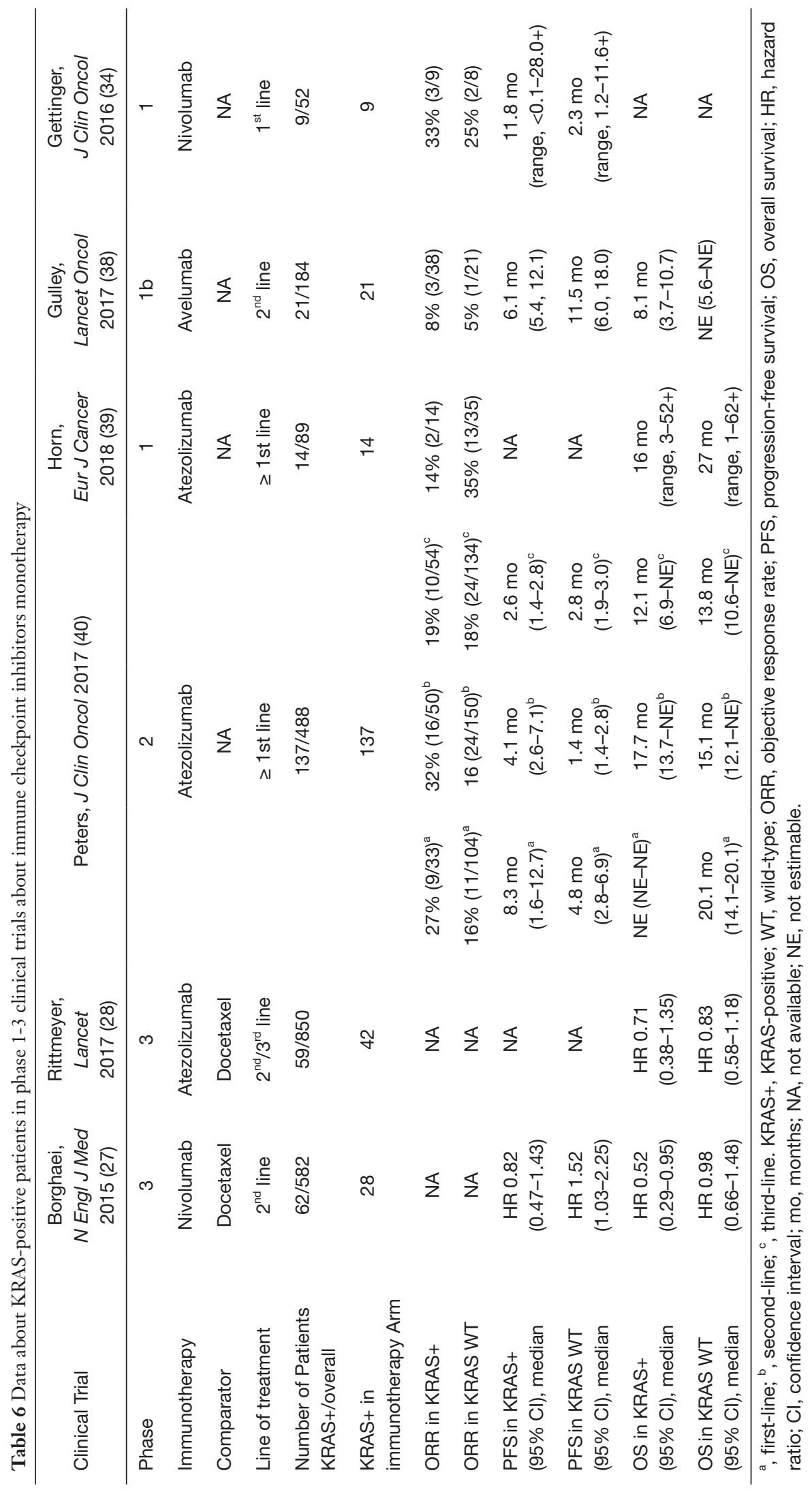



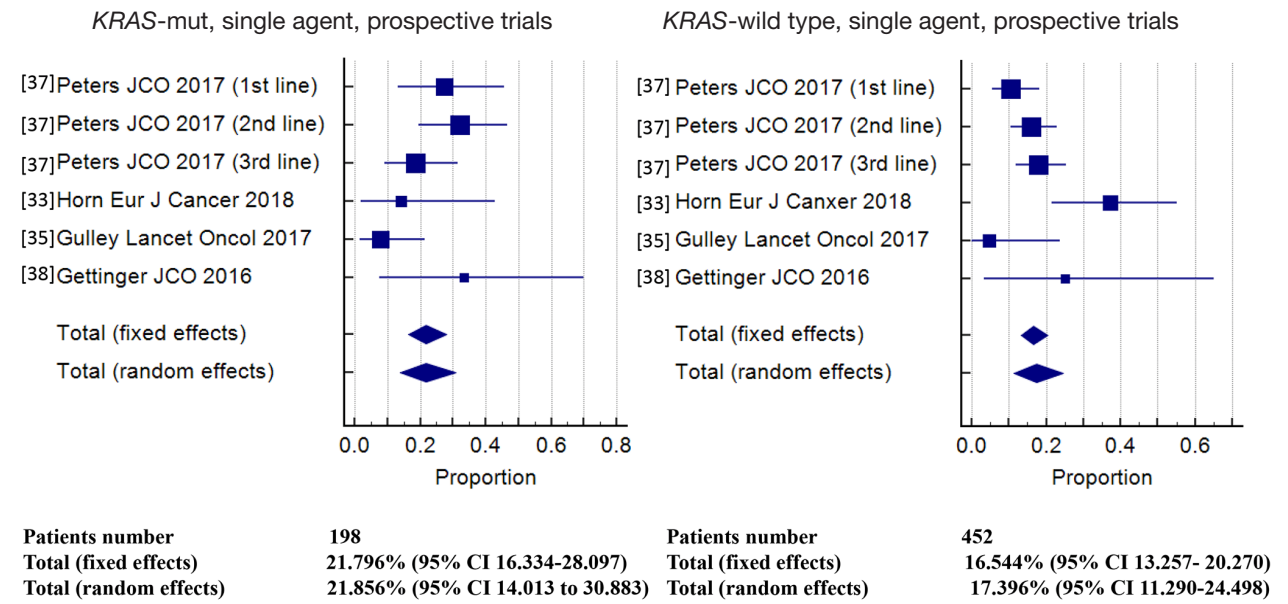

Figure 3 Meta-analysis of objective responses according to $K R A S$ status in prospective trials of single-agent immune checkpoint inhibitors.

responses were observed regardless of $K R A S$ status (91).

No particular toxicities issues have been risen about immunotherapy in KRAS-mutated patients.

\section{Co-existing molecular alterations affecting ICIs activity and efficacy in KRAS-mutated disease}

Within the KRAS-mutant population of NSCLC patients, several entities with a putative prognostic/predictive role in immunotherapy have been recognized. Comutant KRAS/STK11 (up to $30 \%$ of KRAS-positive cases) adenocarcinomas are associated with a "cold" immune micro-environment (119). Indeed, while KRAS mutations are accompanied by relatively high levels of PD-L1 expression and TILs density (see above), STK11 mutational inactivation is characterized by low PD-L1 expression, TILs reduction, accumulation of neutrophils boosting T-cell exhaustion, and a pro-tumoral cytokine milieu (119-121). These characteristics are likely to mechanistically affect the poor outcomes of KRAS/ STK11-mutated NSCLC patients receiving single agent immunotherapy, with a relevant proportion of primary resistance (RR 0-7.4\%; median PFS and OS 1.8 and 6.8 months, respectively) (122). On the other hand, the opposite immune features of KRAS/TP53-mutant tumors (accounting for an 30-40\% of KRAS-positive NSCLC) ostensibly lead to significant benefit observed in patients harboring the two mutational events (RR 35.7-57.1\%; median PFS and OS 3 and 16 months, respectively) $(119,122)$. The co-occurrence of KRAS and STK11 mutations has been moreover proposed as a mutational marker of hyper-progressive disease (HPD) in NSCLC patients receiving ICIs, as all the three patients suffering from KRAS/STK11-positive lung cancer in the series from Kim and colleagues experienced HPD (123).

In another retrospective series with a lower patients' number, the impact of STK11 and TP53 status did not emerge as impacting on ICIs activity and effectiveness in KRAS-mutant NSCLC, while KEAP1 or NFE2L2 mutations negatively affected the prognosis of KRAS-positive NSCLC patients undergoing immunotherapy (117).

Of interest, among $K R A S$-mutated lung cancers only 4\% harbor both STK11 and TP53 mutations, making the occurrence of triple mutation less frequent then expected by chance $(122,124)$.

\section{ALK-driven NSCLC and ICIs}

Perspective evidences, real-life experiences, combinatorial strategies and toxicity issues

Few ALK-positive patients have been enrolled in clinical trials with ICIs, and their outcome is usually not reported. Among $A L K$-rearranged patients treated with pembrolizumab or avelumab in second or subsequent lines, none achieved a response $(27,37,38)$.

Collecting data about retrospective series, $71 \mathrm{ALK}$ rearranged NSCLC have been exposed to ICIs (Table 8). Although no hints on efficacy outcomes can be driven, only 9.6\% (95\% CI: 4.1-17.1) of the patients experienced disease response (Table S9), without significant heterogeneity among studies $\left(\mathrm{I}^{2}=0 \%\right)$. As reported by Mazières and colleagues, PFS-rate at six and 12 months was $12 \%$ and $6 \%$, respectively ( $\mathrm{n}=23$ ALK-positive patients) (68). As 
Table 7 Clinical evidence of immune checkpoint activity and effectiveness in KRAS-mutant non-small cell lung cancer patients

\begin{tabular}{|c|c|c|c|c|c|c|c|c|}
\hline Reference & $\begin{array}{l}\text { Patients KRAS } \\
\text { status }\end{array}$ & CR+PR [\%] & SD [\%] & PD [\%] & $\begin{array}{c}\text { mPFS } \\
(\mathrm{mo})\end{array}$ & $\begin{array}{l}\text { Stats } \\
\text { PFS }\end{array}$ & $\begin{array}{l}\mathrm{mOS} \\
(\mathrm{mo})\end{array}$ & Stats OS \\
\hline $\begin{array}{l}\text { Passiglia, Br J Cancer } \\
2019 \text { (112) }\end{array}$ & MUT 206 & $41[20]^{a}$ & $55[27]^{a}$ & $110[53]$ & 4 & $P=0.56$ & 11.2 & $P=0.86$ \\
\hline Lin, J Cancer 2018 (48) & MUT 10 & $3[30]$ & $3[43]$ & $1[14]$ & 3.8 & $P=0.457$ & 5.9 & $P=0.614$ \\
\hline $\begin{array}{l}\text { Garde-Noguera, Clin } \\
\text { Trans/ Oncol } 2018 \text { (113) }\end{array}$ & WT 32 & $9[26]^{\mathrm{a}}$ & NA & NA & 2.4 & $P=0.345$ & 5.4 & $P=0.299$ \\
\hline \multirow{2}{*}{$\begin{array}{l}\text { Jeanson, J Thorac } \\
\text { Oncol } 2019 \text { (114) }\end{array}$} & MUT 162 & $30[19]^{a}$ & $48[30]^{a}$ & 84 [52] & $3.09^{b}$ & \multirow[t]{2}{*}{$P=0.584$} & $14.29^{b}$ & \multirow[t]{2}{*}{$P=0.682$} \\
\hline & WT 120 & $17[14]^{a}$ & $42[35]^{a}$ & $61[51]$ & $2.66^{\mathrm{b}}$ & & $11.14^{\mathrm{b}}$ & \\
\hline \multirow{2}{*}{$\begin{array}{l}\text { Gianoncelli, Anticancer } \\
\text { Res } 2020 \text { (116) }\end{array}$} & MUT 43 & $8[19]^{a}$ & $14[34]^{a}$ & $19[46]$ & 4.6 & \multirow[t]{2}{*}{$P=0.58$} & 13.0 & \multirow[t]{2}{*}{$P=0.38$} \\
\hline & WT 117 & $32[36]^{\mathrm{a}}$ & $17[19]^{\mathrm{a}}$ & $39[44]$ & 3.3 & & 8.1 & \\
\hline $\begin{array}{l}\text { de Vries, Ann Oncol } \\
2019 \text { (71) }\end{array}$ & KRAS+ 54 & \multicolumn{2}{|c|}{$26[48]$} & 28 [52] & NA & NA & NA & NA \\
\hline $\begin{array}{l}\text { Costantini, Lung Cancer } \\
2019 \text { (76) }\end{array}$ & KRAS+ 50 & \multicolumn{2}{|c|}{42 no early PD [84] } & 8 early PD [16] & NA & NA & NA & NA \\
\hline Ng, Cancer 2019 (61) & KRAS+ 56 & $9[16]$ & $23[41]$ & $24[43]$ & 4.57 & NA & NA & NA \\
\hline $\begin{array}{l}\text { Oya, Oncotarget } 2017 \\
\text { (72) }\end{array}$ & KRAS +14 & $4[28]$ & NA & NA & 1.9 & NA & 6.6 & NA \\
\hline $\begin{array}{l}\text { Guibert, Lung Cancer } \\
2019 \text { (70) }\end{array}$ & KRAS +10 & NA & NA & NA & 7.5 & NA & NA & NA \\
\hline \multirow{3}{*}{$\begin{array}{l}\text { Arbour, } \\
\text { Clin Cancer Res } \\
2018(117)\end{array}$} & KRAS+ only 60 & NA & NA & NA & NA & NA & NR & - \\
\hline & $\begin{array}{l}\text { KRAS+/KEAP1+ or } \\
\text { NFE2L2+ } 26\end{array}$ & & & & & & 6 & $\mathrm{P}=0.006$ (Multiv + ) \\
\hline & KRAS+/STK11+ 26 & & & & & & 11 & 0.3 \\
\hline \multirow{2}{*}{$\begin{array}{l}\text { Gainor, Ann Oncol } \\
2020 \text {, PD-L1 } \\
\geq 50 \% \text { (81) }\end{array}$} & $\begin{array}{c}17 \text { never-light } \\
\text { smokers }\end{array}$ & 4 [23] & NA & NA & NA & NA & NA & \multirow[t]{2}{*}{ NA } \\
\hline & 95 heavy smokers & $40[42]$ & & & & & & \\
\hline
\end{tabular}

${ }^{a}$, not statistically significant. ${ }^{b}$, mean values. MUT, mutated; WT, wild-type; +, positive/mutant; CR, complete responses; PR, partial responses; SD, stable diseases; PD, progressive diseases; NA, not available; Multiv +, positive association at the multivariate analysis; mPFS, median progression-free survival; mo, months; Stats, statistics; mOS, median overall survival. 
Table 8 Clinical evidence of immune checkpoint activity and effectiveness in $A L K$-rearranged non-small cell lung cancer patients

\begin{tabular}{|c|c|c|c|c|c|c|}
\hline Reference & Patients ALK+ & CR+PR [\%] & $\mathrm{SD}[\%]$ & PD [\%] & mPFS (mo) & $\mathrm{mOS}(\mathrm{mo})$ \\
\hline Heo, Thorac Cancer 2019 (125) & 14 & $2[14]$ & $2[14]$ & 9 [64] & 2.2 & 5.7 \\
\hline Fujimoto, Lung Cancer 2018 (51) & 11 & $2[18]$ & $1[8]$ & $8[74]$ & NA & NA \\
\hline Bylicki, Med (Baltimore) 2020 (58) & 8 & $2[25]$ & $2[25]$ & $4[50]$ & 2.4 & 19.2 \\
\hline Ng, Cancer 2019 (61) & 4 & $0[0]$ & $1[25]$ & $3[75]$ & 1.17 & NA \\
\hline Kobayashi, Clin Lung Cancer 2018 (62) & 3 & $0[0]$ & 3 [100] & $0[0]$ & NA & NA \\
\hline Bagley, Lung Cancer 2017 (74) & 3 & $0[0]$ & NA & NA & NA & NA \\
\hline Gainor, Clin Cancer Res $2016^{a}(17)$ & 6 & $0[0]$ & NA & NA & NA & NA \\
\hline
\end{tabular}

a, see Table 3 for additional information. CR, complete responses; PR, partial responses; SD, stable diseases; PD, progressive diseases; $\mathrm{NA}$, not available; mPFS, median progression-free survival; mo, months; mOS, median overall survival.

preclinical models suggest PD-L1 expression induction by EML4-ALK fusion gene (126), the combination of immunotherapy with ALK inhibitors has been largely evaluated. Most evidence are from early phase studies, and efficacy considerations are only partial. Given the extremely positive results in managing ALK-positive disease since the introduction of second- and third-generation TKIs $(127,128)$, the expected readout in this setting of combination is not the achievement of positive ORR, but the obtaining of prolonged responses and the potential reversal of resistance to single-agent TKIs.

Two phase 1-2 trials about combination of crizotinib with an anti-PD-1 agent have been early interrupted and the combination was not recommended. In the Checkmate 370 trial about combination of nivolumab and crizotinib as first-line treatment, severe hepatotoxicity was reported in $38 \%$ (5/13 these evidences and despite $38 \%$ rate of partial response, further evaluations of the combination were therefore not endorsed (129). The trial about combination with pembrolizumab terminated early due to difficult accrual after the advent of second-generation inhibitors, so the maximum tolerated dose was not determined. Of note, of nine enrolled patients, four dose limiting toxicities were reported, with three cases of grade $\geq 3$ transaminase increase (130).

In the phase $1 \mathrm{~b}$ dose escalation trial, ceritinib in combination with nivolumab showed promising activity at both dosages (450 and $300 \mathrm{mg}$ ), especially in treatment naïve patients and in $\mathrm{PD}-\mathrm{L} 1$ positive ones, still with many toxicities, including unusual high rate of rash. Despite its activity, toxicity issues suggest to evaluate different schedules of drug administration, and parameters to select patients more likely to respond to combination would be recommended (131).

The combination of the current standard of care in the first-line setting of $A L K$-rearranged NSCLC, alectinib with atezolizumab seems more manageable in treatmentnaïve patients (132). Of note, in this phase $1 \mathrm{~b}$ trial by Kim et al., alectinib was administered alone for 7 days, and atezolizumab was introduced after this safety evaluation. Despite 6 patients out of 21 discontinued one of two treatments, no severe adverse events were observed and no dose limiting toxicities were reported, ORR was $81 \%$ and mPFS was 21.7 months (95\% CI: 10.3-21.7) (132).

The Javelin lung 101 trial enrolled pretreated ALKpositive and ALK-negative patients based on preclinical assumptions about synergistic activity of ALK inhibitors and immunotherapy in NSCLC (133). Avelumab was administered in combination with crizotinib in ALKnegative patients, or with lorlatinib in $A L K$-rearranged ones (134). The third-generation inhibitor provide an acceptable safety profile and its activity will be further evaluated.

Even if hepatic toxicity is commonly associated with ALK inhibitors (135), immunotherapy seems to increase toxicity rates, but mechanisms behind this amplification are not fully elucidated. The majority of studies are dealing with concomitant therapies, while sequential approaches 
Table 9 Clinical evidence of immune checkpoint activity and effectiveness in $B R A F$-mutant non-small cell lung cancer patients

\begin{tabular}{|c|c|c|c|c|c|c|}
\hline Reference & Patients BRAF status & $\mathrm{CR}+\mathrm{PR}[\%]$ & $\mathrm{SD}[\%]$ & PD [\%] & mPFS (mo) & mOS (mo) \\
\hline $\begin{array}{l}\text { Rihawi, J Thorac } \\
\text { Oncol } 2019 \text { (138) }\end{array}$ & 199 WT & 39 [20] & 45 [23] & $108[54]$ & NA & 11.2 \\
\hline \multirow{2}{*}{$\begin{array}{l}\text { Guisier, J Thorac } \\
\text { Oncol } 2020 \text { (139) }\end{array}$} & 26 V600 & $6[26]$ & 8 [35] & 9 [39] & 5.3 & 22.5 \\
\hline & 18 non-V600 & $6[35]$ & 3 [18] & $8[47]$ & 4.9 & 12 \\
\hline $\begin{array}{l}\text { Schouten, Lung } \\
\text { Cancer } 2018 \text { (73) }\end{array}$ & 5 non-V600E & $3[60]$ & NA & NA & NA & NA \\
\hline \multirow{2}{*}{$\begin{array}{l}\text { Dudnik, J Thorac } \\
\text { Oncol } 2018(140)\end{array}$} & $12 \mathrm{~V} 600 \mathrm{E}$ & $3[25]$ & NA & NA & 3.7 & NR \\
\hline & 10 non-V600E & 3 [33] & NA & NA & 4.1 & NR \\
\hline $\begin{array}{l}\text { Dudnik, Lung } \\
\text { Cancer } 2018 \text { (141) }\end{array}$ & 4 V600E & $1[25]$ & NA & NA & 1.5 & NR \\
\hline Ng, Cancer 2019 (61) & 8 V600E & $2[25]$ & $1[12]$ & $5[63]$ & 2.73 & NA \\
\hline Oya, Oncotarget 2017 (72) & $1 \mathrm{BRAF}+$ & $0[0]$ & NA & NA & NA & NA \\
\hline \multirow{2}{*}{$\begin{array}{l}\text { Gainor, Ann Oncol } 2020(81) \text {, } \\
\text { BRAF+ PD-L1 } \geq 50 \%\end{array}$} & 4 light-never smokers & $1[25]$ & NA & NA & NA & NA \\
\hline & 12 heavy smokers & $6[50]$ & & & & \\
\hline
\end{tabular}

WT, wild-type; CR, complete responses; PR, partial responses; SD, stable diseases; PD, progressive diseases; NA, not available; mPFS, median progression-free survival; mo, months; mOS, median overall survival.

have not been evaluated prospectively. As already noticed in EGFR-mutated disease, in other oncogene-driven ones the use of ICIs before target therapies may also have toxic consequences. A retrospective study evaluated patients harboring $A L K / R O S 1$ rearrangement or MET amplification/mutation treated with crizotinib. Eleven out of 453 received a TKI after a previous ICI (as single agent or in combination strategies). Patients previously treated with immunotherapy experienced higher incidence of hepatotoxicity (reversible in all cases) including grade $3 / 4$ ALT or AST increase reported in $45.5 \%$ and $36.4 \%$ of patients, respectively, suggesting the importance of a careful surveillance in a sequential regimen (135). Still, the reverse strategy in ALK-driven disease has not been evaluated.

\section{BRAF-driven NSCLC and ICIs}

$B R A F$ mutations account for approximately $5 \%$ of lung adenocarcinomas, half of them occurs in codon V600 in exon 15 (namely V600E), the others in codons other than V600 in exon 11 or 15 (136). While dabrafenib-trametinib combination is the novel standard of care for $B R A F^{\mathrm{V} 600 \mathrm{E}}$ mutant NSCLC, scant data are available concerning activity and efficacy of BRAF/MEK inhibitors in non-V600E $B R A F$ mutations $(136,137)$. The repartition between these two groups of $B R A F$-mutated patients has frequently been maintained in retrospective reports dealing with ICIs (Table 9). Activity and efficacy of immunotherapy in $B R A F$ positive disease are satisfactory, recapitulating results observed in KRAS-driven and WT disease. The global limited number of patients in the respective V600 and non-V600 subgroups, as well as the contradictory results reported in some series $(68,139)$, precludes any conclusion regarding a potential differential benefit derived from ICIs. The positive smoking history, frequently observed in $B R A F$ mutant NSCLC $(137,139,140)$, likely contributes to the better outcomes observed (Table S10).

In the largest series published so far, Guisier and colleagues reported slight differences in outcomes in $B R A F^{\mathrm{V} 600}(\mathrm{n}=26)$ and $B R A F^{\mathrm{non}-\mathrm{V} 600}(\mathrm{n}=18)$ patients $(139)$. Half of them received single-agent ICI as a second-line of treatment; PR and disease control were observed in 
approximately $30 \%$ and $60 \%$ of the cases. Median PFS was 5 months, with approximately $50 \%$ and $30 \%$ of the patients not progressing at six and 12 months, respectively at the same landmark time-points, proportions of progression-free patients were $32 \%$ and $18 \%$ in the series of Mazières and colleagues (68). Median OS was 22.5 months in the V600 group and 12 months in the non-V600 one, nevertheless 12 -months OS rates were overlapping ( $50 \%)$. The lack of a specific report of post-ICI treatment does not allow to contemplate the contribution of targeted agents in engendering such positive OS outcomes in $B R A F^{\mathrm{V} 600}$ patients.

\section{ICIs in patients suffering from NSCLC driven by additional oncogenes}

The immune context in which lung tumors harboring other oncogenic aberration arise has not been deeply characterized, nevertheless some information is already available.

Sabari and colleagues reported that, out of 111 MET exon 14 mutated tumors, $37 \%, 22 \%$, and $41 \%$ expressed PD-L1 in $0 \%, 1-49 \%$ and $\geq 50 \%$ of tumor cells, respectively, globally in line with molecularly unselected cohorts of non-squamous NSCLC (142). TMB, on the other hand, was lower in this population of MET-activated NSCLC compared to unselected cases (143).

Among 26 NSCLC cases harboring RET rearrangements, $58 \%, 23 \%$ and $19 \%$ expressed PD-L1 in $0 \%, 1-49 \%$ and $\geq 50 \%$ of tumor cells, while TMB in RET-positive diseases was lower compared to RET-negative ones (11).

Table 10 gather the information concerning activity and effectiveness collected in retrospective series of ICI administration to patients suffering from NSCLC driven by MET or HER2 abnormalities, RET or ROS1 rearrangements. Again with limited global patients' numbers, across these molecular subgroups, the outcomes obtained with ICIs appears globally disappointing (Table S11 for meta-analysis of ORR in RET-positive patients), with the putative exception of MET-driven diseases, where satisfying activity signals can be observed (Table 10), with $36 \%$ and $23 \%$ of the patients not experiencing progression at 6- at 12-month analyses in the series of Mazières and collaborators (68). At the same landmark time-points, PFSrates were $23 \%$ and $14 \%$ for HER2-positive NSCLC, $14 \%$ and $7 \%$ for RET-rearranged diseases (68).

The positive median OS estimations suggest that a meaningful proportion of patients have been exposed to targeted agents after ICIs failure.

Finally, two patients with NTRK mutations were exposed to ICIs, one of them experiencing disease response (140); nevertheless, the assumption that NTRK is known as an actionable and targetable driver in the case of gene rearrangement, question the relevancy of these data.

\section{Discussion}

Although tremendous progresses over the last years, NSCLC treatment is still plagued by resistance issues. In oncogene-addicted NSCLC, the increasing number of target therapies available cannot guarantee a persistent disease control, due to the emergence of acquired resistance, and the recourse to different treatment strategies is almost unavoidable. Immunotherapy, that revolutionized management of thoracic disease, has a controversial role in this setting, as primary resistance frequently turns this disease into refractory to ICIs. Within each specific group of oncogene-addicted NSCLC, additional pathological or molecular characteristics, that may help to select patients more likely to respond to ICIs, have been suggested, while a clear view on this issue of major clinical relevance is required.

Apart from isolated good responses, evidence suggest that EGFR mutations may be a biomarker of poor response to single-agent immunotherapy. On the contrary, in $E G F R$-positive patients, the combination of atezolizumab + bevacizumab + chemotherapy at the failure of previous TKIs, merges its effectiveness with an acceptable safety profile (85).

$K R A S$-mutated disease usually shows different clinical and pathological characteristics, but co-existing mutations may influence tumor microenvironment and response to single-agent ICIs $(119,122)$.

As already demonstrated with $E G F R$-positive disease, synergistic effects of chemotherapy, antiangiogenic agents and immunotherapy improve outcome of oncogeneaddicted patients (85). At the failure of target therapies, combination strategies are probably the best way to exploit immunotherapy effects, but a careful selection of patients is necessary, considering increased treatment toxicities (85).

Moreover, it is quite common in this setting to use single-agent immunotherapy as last treatment option, when patients' performance status has already worsened, and this may limit its efficacy (145). Moving ICIs in an earlier setting in patients' disease history could favorize their action.

With regard to further molecular alterations, such as 
Table 10 Clinical evidence of immune checkpoint activity and effectiveness in non-small cell lung cancer patients harboring $M E T$ or $H E R 2$ alterations, RET or ROS1 rearrangements

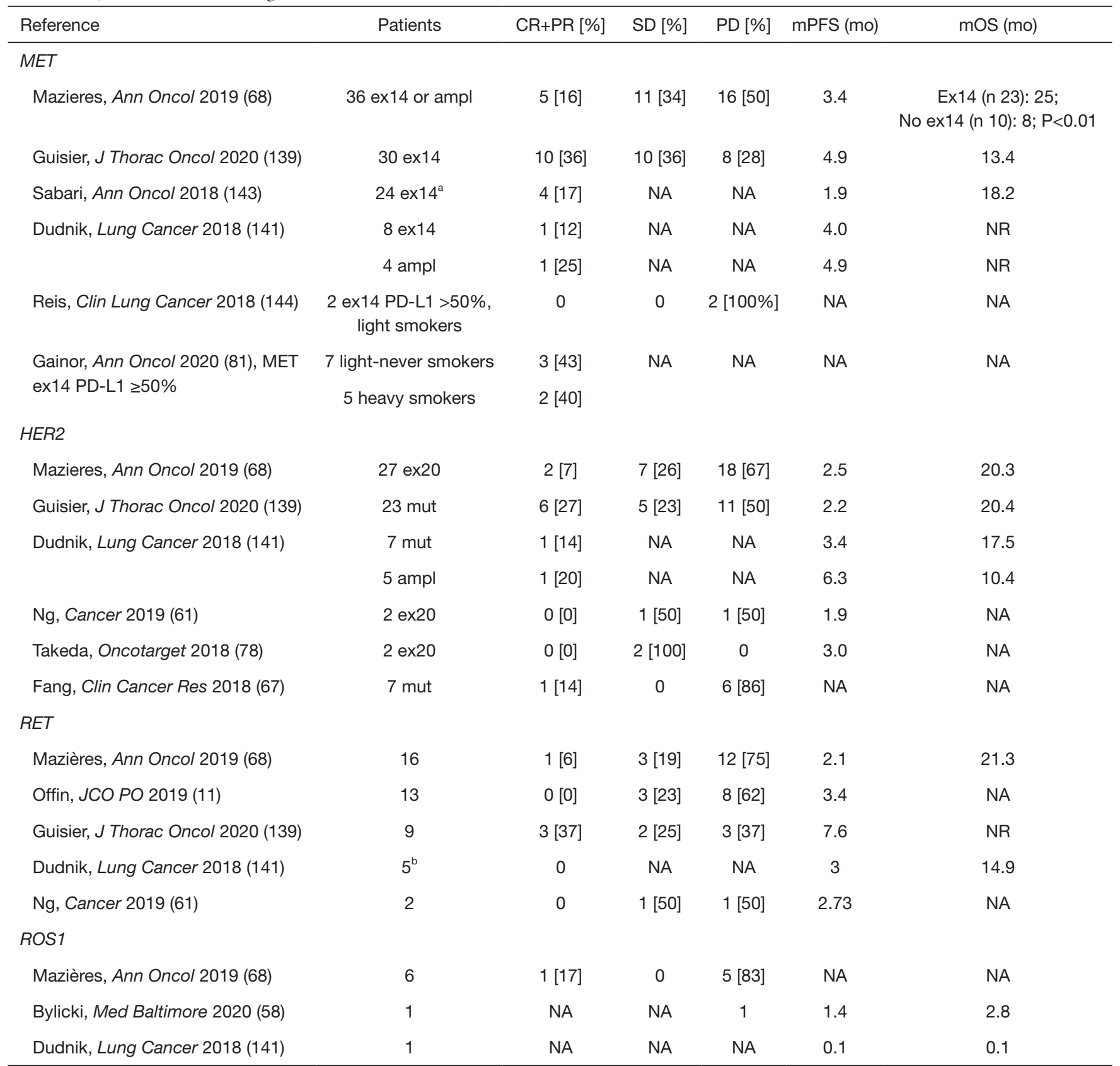

a, 11 received immunotherapy as first-line treatment, two received anti-PD-1/anti-CTLA-4 combination treatment. ${ }^{\mathrm{b}}$, one patient with RETmutated disease. ex 14, Exon 14 skipping mutations; ampl, Amplified; ex 20, Exon 20 mutations; mut, mutated; CR, complete responses; PR, partial responses; SD, stable diseases; PD, progressive diseases; NA, not available; mPFS, Median progression-free survival; mo, months; mOS, median overall survival; NR, not reached.

ALK, BRAF, MET, HER2, RET and ROS1, perspective evidences are lacking. ICIs in $A L K$-rearranged disease have been marginally considered prospectively, but retrospective evidences are not encouraging. Given similarities between $A L K$ and ROS1 rearrangements, it is conceivable that immunotherapy in this subgroup may lack of effectiveness. 
Differently, in $B R A F$ or MET-driven NSCLC some signals of activity have been reported $(68,139)$. Patients suffering from advanced, oncogene-addicted NSCLC suitable for targeted treatment should be exposed to all available lines of potentially active and effective kinase inhibitors, and then evaluated for the best setting of ICIs administration. Leaving immunotherapy in the post-TKI setting reduces in addition the risk of unexpected toxicities, as they are far more common when ICIs are administered before targeted therapies (89).

ICIs and TKIs will likely contribute as game changers also in the management of early stage NSCLC in the next future (146-150), with immunotherapy already being the standard of care in locally advanced NSCLC after chemoradiotherapy $(42,43)$ regardless of mutational status. Molecular characterization will become fundamental even in early stage disease, to define the best treatment strategy and its integration with loco-regional treatments, especially in oncogene-addicted disease.

\section{Acknowledgments}

Funding: None.

\section{Footnote}

Provenance and Peer Review: This article was commissioned by the Guest editors (Jordi Remon and Benjamin Besse) for the series "Immunotherapy in other thoracic malignancies and uncommon populations" published in Translational Lung Cancer Research. The article has undergone external peer review.

Reporting Checklist: The authors have completed the PRISMA reporting checklist. Available at http://dx. doi. org/10. 21037/tlcr-20-941

Peer Review File: Available at http://dx. doi. org/10.21037/ tlcr-20-941

Conflicts of Interest: All authors have completed the ICMJE uniform disclosure form (available at http://dx. doi. org/10. 21037/tlcr-20-941). The series "Immunotherapy in other thoracic malignancies and uncommon populations" was commissioned by the editorial office without any funding or sponsorship. M Tiseo serves as an unpaid editorial board member of Translational Lung Cancer Research from Dec 2014 to Nov 2021. M Tiseo reports grants and personal fees from Astra-Zeneca, grants and personal fees from Boehringer Ingelheim, grants from Pfizer, personal fees from Eli-Lilly, personal fees from BMS, grants and personal fees from Novartis, grants and personal fees from Roche, grants and personal fees from MSD, grants from Otsuka, grants from Pierre Fabre, outside the submitted work. M Di Maio reports personal fees from Astra-Zeneca, personal fees from Pfizer, personal fees from BMS, personal fees from MSD, personal fees from Eisai, personal fees from Janssen, personal fees from Astellas, personal fees from Takeda, grants from Tesaro-GSK, outside the submitted work. F Facchinetti reports personal fees from BMS, personal fees from Roche, outside the submitted work. The authors have no other conflicts of interest to declare.

Ethical Statement: The authors are accountable for all aspects of the work in ensuring that questions related to the accuracy or integrity of any part of the work are appropriately investigated and resolved.

Open Access Statement: This is an Open Access article distributed in accordance with the Creative Commons Attribution-NonCommercial-NoDerivs 4.0 International License (CC BY-NC-ND 4.0), which permits the noncommercial replication and distribution of the article with the strict proviso that no changes or edits are made and the original work is properly cited (including links to both the formal publication through the relevant DOI and the license). See: https://creativecommons.org/licenses/by-nc-nd/4.0/.

\section{References}

1. Camidge DR, Doebele RC, Kerr KM. Comparing and contrasting predictive biomarkers for immunotherapy and targeted therapy of NSCLC. Nat Rev Clin Oncol 2019;16:341-55.

2. Kris MG, Johnson BE, Berry LD, et al. Using Multiplexed Assays of Oncogenic Drivers in Lung Cancers to Select Targeted Drugs. JAMA 2014;311:1998-2006.

3. Slebos RJ, Kibbelaar RE, Dalesio O, et al. K-ras oncogene activation as a prognostic marker in adenocarcinoma of the lung. N Engl J Med 1990;323:561-5.

4. Moore AR, Rosenberg SC, McCormick F, et al. RAStargeted therapies: is the undruggable drugged? Nat Rev Drug Discov 2020;19:533-52.

5. Barlesi F, Mazieres J, Merlio JP, et al. Routine molecular profiling of patients with advanced non-small-cell lung cancer: results of a 1-year nationwide programme of the 
French Cooperative Thoracic Intergroup (IFCT). Lancet 2016;387:1415-26.

6. Shi Y, Au JS, Thongprasert S, et al. A Prospective, molecular epidemiology study of EGFR mutations in Asian patients with advanced non-small-cell lung cancer of adenocarcinoma histology (PIONEER). J Thorac Oncol 2014;9:154-62.

7. Dearden S, Stevens J, Wu YL, et al. Mutation incidence and coincidence in non small-cell lung cancer: metaanalyses by ethnicity and histology (mutMap). Ann Oncol 2013;24:2371-6.

8. Koivunen JP, Mermel C, Zejnullahu K, et al. EML4-ALK fusion gene and efficacy of an ALK kinase inhibitor in lung cancer. Clin Cancer Res 2008;14:4275-83.

9. Recondo G, Facchinetti F, Olaussen KA, et al. Making the first move in EGFR-driven or ALK-driven NSCLC: firstgeneration or next-generation TKI? Nat Rev Clin Oncol 2018;15:694-708.

10. Remon J, Hendriks LE, Cabrera C, et al. Immunotherapy for oncogenic-driven advanced non-small cell lung cancers : Is the time ripe for a change ? Cancer Treat Rev 2018;71:47-58.

11. Offin M, Guo R, Wu SL, et al. Immunophenotype and Response to Immunotherapy of RET -Rearranged Lung Cancers. JCO Precis Oncol 2019;3:PO.18.00386.

12. Abdel-Rahman O. Smoking and EGFR status may predict outcomes of advanced NSCLC treated with PD- (L)1 inhibitors beyond first line: A meta-analysis. Clin Respir J 2018;12:1809-19.

13. Mo J, Hu X, Gu L, al. Smokers or non-smokers: who benefits more from immune checkpoint inhibitors in treatment of malignancies ? An up-to- date meta-analysis. World J Surg Oncol 2020;18:15.

14. Rizvi NA, Hellmann MD, Snyder A, et al. Mutational landscape determines sensitivity to PD-1 blockade in nonsmall cell lung cancer. Science 2015;348:124-8.

15. Nagahashi M, Sato S, Yuza K, et al. Common driver mutations and smoking history affect tumor mutation burden in lung adenocarcinoma. J Surg Res 2018;230:181-5.

16. Ozaki $\mathrm{Y}$, Muto S, Takagi H, et al. Tumor mutation burden and immunological, genomic, and clinicopathological factors as biomarkers for checkpoint inhibitor treatment of patients with non-small-cell lung cancer. Cancer Immunol Immunother 2020;69:127-34.

17. Gainor JF, Shaw AT, Sequist LV, et al. EGFR Mutations and ALK Rearrangements Are Associated with Low Response Rates to PD-1 Pathway Blockade in Non-Small
Cell Lung Cancer: A Retrospective Analysis. Clin Cancer Res 2016;22:4585-93.

18. Liu SY, Dong ZY, Wu SP, et al. Clinical relevance of PD$\mathrm{L} 1$ expression and CD8 $+\mathrm{T}$ cells infiltration in patients with EGFR-mutated and ALK-rearranged lung cancer. Lung Cancer 2018;125:86-92.

19. Toki MI, Mani N, Smithy JW, et al. Immune marker profiling and programmed death ligand 1 expression across NSCLC mutations. J Thorac Oncol 2018;13:1884-96.

20. Dong ZY, Zhang JT, Liu SY, et al. EGFR mutation correlates with uninflamed phenotype and weak immunogenicity, causing impaired response to PD-1 blockade in non-small cell lung cancer. Oncoimmunology 2017;6:e1356145.

21. Huynh TG, Morales-Oyarvide V, Campo MJ, et al. Programmed Cell Death Ligand 1 Expression in Resected Lung Adenocarcinomas: Association with Immune Microenvironment. J Thorac Oncol 2016;11:1869-78.

22. Isomoto K, Haratani K, Hayashi H, et al. Impact of EGFR-TKI Treatment on the Tumor Immune Microenvironment in EGFR Mutation-Positive Non-Small Cell Lung Cancer. Clin Cancer Res 2020;26:2037-46.

23. Chen N, Fang W, Zhan J, et al. Upregulation of PDL1 by EGFR Activation Mediates the Immune Escape in EGFR-Driven NSCLC: Implication for Optional Immune Targeted Therapy for NSCLC Patients with EGFR Mutation. J Thorac Oncol 2015;10:910-23.

24. Zhang N, Zeng Y, Du W, et al. The EGFR pathway is involved in the regulation of PD-L1 expression via the IL-6/JAK/STAT3 signaling pathway in EGFR-mutated non-small cell lung cancer. Int J Oncol 2016;49:1360-8.

25. Hui R, Garon EB, Goldman JW, et al. Pembrolizumab as first-line therapy for patients with PD-L1-positive advanced non-small cell lung cancer: a phase 1 trial. Ann Oncol 2017;28:874-81.

26. Gettinger S, Horn L, Jackman D, et al. Five-Year FollowUp of Nivolumab in Previously Treated Advanced NonSmall-Cell Lung Cancer: Results From the CA209-003 Study. J Clin Oncol 2018;36:1675-84.

27. Borghaei H, Paz-Ares L, Horn L, et al. Nivolumab versus docetaxel in advanced nonsquamous nonsmall-cell lung cancer. N Engl J Med 2015;373:1627-39.

28. Rittmeyer A, Barlesi F, Waterkamp D, et al. Atezolizumab versus docetaxel in patients with previously treated non-small-cell lung cancer (OAK): a phase 3, openlabel, multicentre randomised controlled trial. Lancet 2017;389:255-65. 
29. von Pawel J, Bordoni R, Satouchi M, et al. Long-term survival in patients with advanced non e small-cell lung cancer treated with atezolizumab versus docetaxel: Results from the randomised phase III OAK study. Eur J Cancer 2019;107:124-32.

30. Fehrenbacher L, Spira A, Ballinger M, et al. Atezolizumab versus docetaxel for patients with previously treated non-small-cell lung cancer (POPLAR): a multicentre, open-label, phase 2 randomised controlled trial. Lancet 2016;387:1837-46.

31. Herbst RS, Baas P, Kim DW, et al. Pembrolizumab versus docetaxel for previously treated, PD-L1-positive, advanced non-small-cell lung cancer (KEYNOTE-010): a randomised controlled trial. Lancet 2016;387:1540-50.

32. Hida T, Kaji R, Satouchi M, et al. Atezolizumab in Japanese Patients With Previously Treated Advanced Non e Small-Cell Lung Cancer: A Subgroup Analysis of the Phase 3 OAK Study. Clin Lung Cancer 2018;19:e405-15.

33. Gettinger SN, Horn L, Gandhi L, et al. Overall survival and long-term safety of nivolumab (anti-programmed death 1 antibody, BMS-936558, ONO-4538) in patients with previously treated advanced non-small-cell lung cancer. J Clin Oncol 2015;33:2004-12.

34. Gettinger S, Rizvi NA, Chow LQ, et al. Nivolumab Monotherapy for First-Line Treatment of Advanced NonSmall-Cell Lung Cancer. J Clin Oncol 2016;34:2980-7.

35. Nishio M, Hida T, Atagi S, et al. Multicentre phase II study of nivolumab in Japanese patients with advanced or recurrent non-squamous non-small cell lung cancer. ESMO Open 2017;1:e000108.

36. Leighl NB, Hellmann MD, Hui R, et al. Pembrolizumab in patients with advanced non-small-cell lung cancer (KEYNOTE-001): 3-year results from an open-label, phase 1 study. Lancet Respir Med 2019;7:347-57.

37. Nishio M, Takahashi T, Yoshioka H, et al.

KEYNOTE-025: Phase 1b study of pembrolizumab in Japanese patients with previously treated programmed death ligand 1-positive advanced non-small-cell lung cancer. Cancer Sci 2019;110:1012-20.

38. Gulley JL, Rajan A, Spigel DR, et al. Avelumab for patients with previously treated metastatic or recurrent non-smallcell lung cancer (JAVELIN Solid Tumor): dose-expansion cohort of a multicentre, open-label, phase $1 \mathrm{~b}$ trial. Lancet Oncol 2017;18:599-610.

39. Horn L, Gettinger SN, Gordon MS, et al. Safety and clinical activity of atezolizumab monotherapy in metastatic non-small-cell lung cancer: final results from a phase I study. Eur J Cancer 2018;101:201-9.
40. Peters S, Gettinger S, Johnson ML, et al. Phase II Trial of Atezolizumab As First-Line or Subsequent Therapy for Patients With Programmed Death-Ligand 1-Selected Advanced Non-Small-Cell Lung Cancer (BIRCH). J Clin Oncol 2017;35:2781-9.

41. Chen YM, Chih-Hsin Yang JC, Su WC, et al. Nivolumab safety and efficacy in advanced, platinum-resistant, nonsmall cell lung cancer, radical radiotherapy-ineligible patients: A phase II study in Taiwan. J Formos Med Assoc 2020;119:1817-26.

42. Antonia SJ, Villegas A, Daniel D, et al. Durvalumab after Chemoradiotherapy in Stage III Non-Small-Cell Lung Cancer. N Engl J Med 2017;377:1919-29.

43. Antonia SJ, Villegas A, Daniel D, et al. Overall Survival with Durvalumab after Chemoradiotherapy in Stage III NSCLC. N Engl J Med 2018;379:2342-50.

44. Garassino MC, Gelibter AJ, Grossi F, et al. Italian Nivolumab Expanded Access Program in Nonsquamous Non-Small Cell Lung Cancer Patients: Results in NeverSmokers and EGFR-Mutant Patients. J Thorac Oncol 2018;13:1146-55.

45. Morita R, Okishio K, Shimizu J, et al. Real-world effectiveness and safety of nivolumab in patients with non-small cell lung cancer: A multicenter retrospective observational study in Japan. Lung Cancer 2020;140:8-18.

46. Yamaguchi O, Kaira K, Hashimoto K, et al. Radiotherapy is an independent prognostic marker of favorable prognosis in non-small cell lung cancer patients after treatment with the immune checkpoint inhibitor, nivolumab. Thorac Cancer 2019;10:992-1000.

47. Ishii H, Azuma K, Kawahara A, et al. Predictive value of CD73 expression for the efficacy of immune checkpoint inhibitors in NSCLC. Thorac Cancer 2020;11:950-5.

48. Lin SY, Yang CY, Liao BC, et al. Tumor PD-L1 Expression and Clinical Outcomes in Advanced-stage NonSmall Cell Lung Cancer Patients Treated with Nivolumab or Pembrolizumab: Real-World Data in Taiwan. J Cancer 2018;9:1813-20.

49. Omori M, Okuma Y, Hakozaki T, et al. Statins improve survival in patients previously treated with nivolumab for advanced non - small cell lung cancer: An observational study. Mol Clin Oncol 2019;10:137-43.

50. Ahn BC, Pyo KH, Xin CF, et al. Comprehensive analysis of the characteristics and treatment outcomes of patients with non-small cell lung cancer treated with anti-PD-1 therapy in real-world practice. J Cancer Res Clin Oncol 2019;145:1613-23.

51. Fujimoto D, Yoshioka H, Kataoka Y, et al. Efficacy and 
safety of nivolumab in previously treated patients with non-small cell lung cancer: A multicenter retrospective cohort study. Lung Cancer 2018;119:14-20.

52. Kobayashi H, Omori S, Nakashima K, et al. Response to the treatment immediately before nivolumab monotherapy may predict clinical response to nivolumab in patients with non-small cell lung cancer. Int J Clin Oncol 2017;22:690-7.

53. Cho JH, Jung HA, Lee SH, et al. Impact of EGFR mutation on the clinical efficacy of PD-1 inhibitors in patients with pulmonary adenocarcinoma. J Cancer Res Clin Oncol 2019;145:1341-9.

54. Juergens RA, Mariano C, Jolivet J, et al. Real-world benefit of nivolumab in a Canadian non-small-cell lung cancer cohort. Curr Oncol 2018;25:384-92.

55. Hsu JC, Lin JY, Hsu MY, et al. Effectiveness and safety of immune checkpoint inhibitors: A retrospective study in Taiwan. PLoS One 2018;13:e0202725.

56. Areses Manrique MC, Mosquera Martínez J, García González J, et al. Real world data of nivolumab for previously treated non-small cell lung cancer patients: a Galician lung cancer group clinical experience. Transl Lung Cancer Res 2018;7:404-15.

57. Kim HK, Heo MH, Lee HS, et al. Comparison of RECIST to immune-related response criteria in patients with non-small cell lung cancer treated with immunecheckpoint inhibitors. Cancer Chemother Pharmacol 2017;80:591-8.

58. Bylicki O, Guisier F, Monnet I, et al. Efficacy and safety of programmed cell-death-protein-1 and its ligand inhibitors in pretreated patients with epidermal growthfactor receptor-mutated or anaplastic lymphoma kinasetranslocated lung adenocarcinoma. Medicine (Baltimore) 2020;99:e18726.

59. Sakamoto H, Tanaka H, Shiratori T, et al. The efficacy of immune checkpoint inhibitors in advanced non-small cell lung cancer harboring driver mutations. Mol Clin Oncol 2019;10:610-4.

60. Sato M, Watanabe S, Tanaka H, et al. Retrospective analysis of antitumor effects and biomarkers for nivolumab in NSCLC patients with EGFR mutations. PLoS One 2019; 14:e0215292.

61. Ng TL, Liu Y, Dimou A, et al. Predictive Value of Oncogenic Driver Subtype, Programmed Death-1 Ligand (PD-L1) Score, and Smoking Status on the Efficacy of PD-1/PD-L1 Inhibitors in Patients With Oncogene-Driven Non-Small Cell Lung Cancer. Cancer 2019;125:1038-49.
62. Kobayashi K, Nakachi I, Naoki K, et al. Real-world Efficacy and Safety of Nivolumab for Advanced Non Small-cell Lung Cancer: A Retrospective Multicenter Analysis. Clin Lung Cancer 2018;19:e349-58.

63. Yoshida H, Kim YH, Ozasa H, et al. Nivolumab in nonsmall-cell lung cancer with EGFR mutation. Ann Oncol 2018;29:777-8.

64. Haratani K, Hayashi H, Tanaka T, et al. Tumor immune microenvironment and nivolumab efficacy in EGFR mutation-positive non-small-cell lung cancer based on T790M status after disease progression during EGFRTKI treatment. Ann Oncol 2017;28:1532-9.

65. Yamada T, Hirai S, Katayama Y, et al. Retrospective efficacy analysis of immune checkpoint inhibitors in patients with EGFR-mutated non-small cell lung cancer. Cancer Med 2019;8:1521-9.

66. Song P, Zhang J, Shang C, et al. Real-world evidence and clinical observations of the treatment of advanced nonsmall cell lung cancer with PD-1/PD-L1 inhibitors. Sci Rep 2019;9:4278.

67. Fang W, Ma Y, Yin JC, et al. Comprehensive Genomic Profiling Identifies Novel Genetic Predictors of Response to Anti-PD-(L)1 Therapies in Non-Small Cell Lung Cancer. Clin Cancer Res 2019;25:5015-26.

68. Mazieres J, Drilon A, Lusque A, et al. Immune checkpoint inhibitors for patients with advanced lung cancer and oncogenic driver alterations: results from the IMMUNOTARGET registry. Ann Oncol 2019;30:1321-8.

69. Hastings K, Yu HA, Wei W, et al. EGFR mutation subtypes and response to immune checkpoint blockade treatment in non-small-cell lung cancer. Ann Oncol 2019;30:1311-20.

70. Guibert N, Jones G, Beeler JF, et al. Targeted sequencing of plasma cell-free DNA to predict response to PD1 inhibitors in advanced non-small cell lung cancer. Lung Cancer 2019;137:1-6.

71. de Vries R, Muller M, van der Noort V, et al. Prediction of response to anti-PD-1 therapy in patients with non-smallcell lung cancer by electronic nose analysis of exhaled breath. Ann Oncol 2019;30:1660-6.

72. Oya Y, Yoshida T, Kuroda H, et al. Predictive clinical parameters for the response of nivolumab in pretreated advanced non-small-cell lung cancer. Oncotarget 2017;8:103117-28.

73. Schouten RD, Muller M, de Gooijer CJ, et al. Real life experience with nivolumab for the treatment of nonsmall cell lung carcinoma: Data from the expanded access 
program and routine clinical care in a tertiary cancer centre-The Netherlands Cancer Institute. Lung Cancer 2018;126:210-16.

74. Bagley SJ, Kothari S, Aggarwal C, et al. Pretreatment neutrophil-to-lymphocyte ratio as a marker of outcomes in nivolumab-treated patients with advanced non-small-cell lung cancer. Lung Cancer 2017;106:1-7.

75. Rizvi H, Sanchez-Vega F, La K, et al. Molecular determinants of response to anti-programmed cell death (PD)-1 and anti-programmed death-ligand 1 (PD-L1) blockade in patients with non-small-cell lung cancer profiled with targeted next-generation sequencing. J Clin Oncol 2018;36:633-41.

76. Costantini A, Fallet V, Corny J, et al. Nivolumabrefractory patients with advanced non-small-cell lung cancer. Lung Cancer 2019;130:128-34.

77. Kitadai R, Okuma Y, Hakozaki T, et al. The efficacy of immune checkpoint inhibitors in advanced non-small-cell lung cancer with liver metastases. J Cancer Res Clin Oncol 2020;146:777-85.

78. Takeda M, Sakai K, Hayashi H, et al. Clinical characteristics of non-small cell lung cancer harboring mutations in exon 20 of EGFR or HER2. Oncotarget 2018;9:21132-40.

79. Taniguchi Y, Tamiya A, Ishii S, et al. Effect of pembrolizumab on patients harboring uncommon epidermal growth factor receptor mutations. Ann Oncol 2018;29:1331-3.

80. Landi L, D'Incà F, Gelibter A, et al. Bone metastases and immunotherapy in patients with advanced non-small-cell lung cancer. J Immunother Cancer 2019;7:316.

81. Gainor JF, Rizvi H, Jimenez Aguilar E, et al. Clinical activity of programmed cell death 1 (PD-1) blockade in never, light, and heavy smokers with non-small-cell lung cancer and PD-L1 expression $\geq 50 \%$. Ann Oncol 2020;31:404-11.

82. Ferrara R, Pilotto S, Caccese M, et al. Do immune checkpoint inhibitors need new studies methodology? J Thorac Dis 2018;10:S1564-80.

83. Rebuzzi SE, Leonetti A, Tiseo M, et al. Advances in the prediction of long-term effectiveness of immune checkpoint blockers for non-small-cell lung cancer. Immunotherapy 2019;11:993-1003.

84. Hu-Lieskovan S, Lisberg A, Zaretsky JM, et al. Tumor Characteristics Associated with Benefit from Pembrolizumab in Advanced Non-Small Cell Lung Cancer. Clin Cancer Res 2019;25:5061-8.

85. Reck M, Mok TSK, Nishio M, et al. Atezolizumab plus bevacizumab and chemotherapy in non-small-cell lung cancer (IMpower150): key subgroup analyses of patients with EGFR mutations or baseline liver metastases in a randomised, open-label phase 3 trial. Lancet Respir Med 2019;7:387-401.

86. Rizvi NA, Hellmann MD, Brahmer JR, et al.

Nivolumab in Combination With Platinum-Based Doublet Chemotherapy for First-Line Treatment of Advanced Non-Small-Cell Lung Cancer. J Clin Oncol 2016;34:2969-79.

87. Hellmann MD, Rizvi NA, Goldman JW, et al. Nivolumab plus ipilimumab as first-line treatment for advanced nonsmall-cell lung cancer (CheckMate 012): results of an open-label, phase 1, multicohort study. Lancet Oncol 2017;18:31-41.

88. Gettinger S, Hellmann MD, Chow LQM, et al. Nivolumab Plus Erlotinib in Patients With EGFR -Mutant Advanced NSCLC. J Thorac Oncol 2018;13:1363-72.

89. Lisberg A, Cummings A, Goldman JW, et al. A phase II study of pembrolizumab in EGFR-mutant, PD$\mathrm{L} 1+$ tyrosine kinase inhibitor (TKI) naive patients with advanced NSCLC. J Thorac Oncol 2018;13:1138-45.

90. Gubens MA, Sequist LV, Stevenson JP, et al. Pembrolizumab in combination with ipilimumab as second-line or later therapy for advanced non-small-cell lung cancer: KEYNOTE-021 cohorts D and H. Lung Cancer 2019;130:59-66.

91. Hellmann MD, Kim TW, Lee CB, et al. Phase Ib study of atezolizumab combined with cobimetinib in patients with solid tumors. Ann Oncol 2019;30:1134-42.

92. Socinski MA, Jotte RM, Cappuzzo F, et al. Atezolizumab for First-Line Treatment of Metastatic Nonsquamous NSCLC. N Engl J Med 2018;378:2288-301.

93. Herbst RS, Arkenau HT, Santana-Davila R, et al. Ramucirumab plus pembrolizumab in patients with previously treated advanced non-small-cell lung cancer, gastro-oesophageal cancer, or urothelial carcinomas (JVDF): a multicohort, non-randomised, open-label, phase 1a / b trial. Lancet Oncol 2019;20:1109-23.

94. Wrangle JM, Velcheti V, Patel MR, et al. ALT-803, an IL-15 superagonist, in combination with nivolumab in patients with metastatic non-small cell lung cancer: a nonrandomised, open-label, phase $1 \mathrm{~b}$ trial. Lancet Oncol 2018;19:694-704.

95. Yasuda H, Kobayashi S, Costa DB. EGFR exon 20 insertion mutations in non-small-cell lung cancer: preclinical data and clinical implications. Lancet Oncol 2012;13:e23-31. 
96. Yasuda H, Park E, Yun CH, et al. Structural, biochemical and clinical characterization of epidermal growth factor receptor (EGFR) exon 20 insertion mutations in lung cancer. Sci Transl Med 2013;5:216ra177.

97. Oxnard GR, Yang JC, Yu H, et al. TATTON: a multi-arm, phase Ib trial of osimertinib combined with selumetinib, savolitinib, or durvalumab in EGFR-mutant lung cancer. Ann Oncol 2020;31:507-16.

98. Yang JC, Shepherd FA, Kim DW, et al. Osimertinib Plus Durvalumab versus Osimertinib Monotherapy in EGFR T790M-Positive NSCLC following Previous EGFR TKI Therapy: CAURAL Brief Report. J Thorac Oncol 2019;14:933-9.

99. Gibbons DL, Chow LQ, Kim DW, et al. 570 Efficacy, safety and tolerability of MEDI4736 (durvalumab [D]), a human IgG1 anti-programmed cell death-ligand-1 (PDL1) antibody, combined with gefitinib (G): a phase I expansion in TKI-naive patients (pts) with EGFR mutant NSCLC. J Thorac Oncol 2016;11:S79.

100. Ma BBY, Rudin CM, Cervantes A, et al. Preliminary safety and clinical activity of erlotinib plus atezolizumab from a phase Ib study in advanced NSCLC. Ann Oncol 2016;27:ix139-56.

101.Schoenfeld AJ, Arbour KC, Rizvi H, et al. Severe immune-related adverse events are common with sequential PD-(L)1 blockade and osimertinib. Ann Oncol 2019;30:839-44.

102. Uchida T, Kaira K, Yamaguchi O, et al. Different incidence of interstitial lung disease according to different kinds of EGFR-tyrosine kinase inhibitors administered immediately before and/or after anti-PD-1 antibodies in lung cancer. Thorac Cancer 2019;10:975-9.

103. Oshima Y, Tanimoto T, Yuji K, et al. EGFR-TKIAssociated Interstitial Pneumonitis in Nivolumab-Treated Patients With Non-Small Cell Lung Cancer. JAMA Oncol 2018;4:1112-5.

104. Yamaguchi O, Kaira K, Kawasaki T, et al. Severe hepatotoxicity due to osimertinib after nivolumab therapy in patients with non-small cell lung cancer harboring EGFR mutation. Thorac Cancer 2020;11:1045-51.

105. Takenaka T, Yamazaki K, Miura N, et al. Osimertinib reactivated immune-related colitis after treatment with anti-PD1 antibody for non-small cell lung cancer. Invest New Drugs 2017;35:848-50.

106. Planchard D, Popat S, Kerr K, et al. Metastatic Non-Small Cell Lung Cancer: ESMO Clinical Practice Guidelines for Diagnosis, Treatment and Follow-Up. Ann Oncol 2018;29:iv192-237.
107.Passiglia F, Pilotto S, Facchinetti F, et al. Treatment of advanced non-small-cell lung cancer: The 2019 AIOM (Italian Association of Medical Oncology) clinical practice guidelines. Crit Rev Oncol Hematol 2020;146:102858.

108. Song P, Guo L, Li W, et al. Clinicopathologic Correlation With Expression of PD-L1 on Both Tumor Cells and Tumor-infiltrating Immune Cells in Patients With NonSmall Cell Lung Cancer. J Immunother 2019;42:23-8.

109. Falk AT, Yazbeck N, Guibert N, et al. Effect of mutant variants of the KRAS gene on PD-L1 expression and on the immune microenvironment and association with clinical outcome in lung adenocarcinoma patients. Lung Cancer 2018;121:70-5.

110. Gadgeel S, Rodriguez-Abreu D, Felip E, et al. KRAS mutational status and efficay in KEYNOTE-189: pembrolizumab plus chemotherapy vs placebo plus chemo as first line therapy for metastatic non-squamous NSCLC. ESMO Immuno-Oncology Congress 2019. Abstract

Book of ESMO Immuno-Oncology Congress 2019 11-14 December 2019, Geneva, Switzerland.

111. Fehrenbacher L, von Pawel J, Park K, et al. Updated Efficacy Analysis Including Secondary Population Results for OAK: A Randomized Phase III Study of Atezolizumab versus Docetaxel in Patients with Previously Treated Advanced Non-Small Cell Lung Cancer. J Thorac Oncol 2018;13:1156-70.

112.Passiglia F, Cappuzzo F, Alabiso O, et al. Efficacy of nivolumab in pre-treated non-small-cell lung cancer patients harbouring KRAS mutations. Br J Cancer 2019;120:57-62.

113. Garde-Noguera J, Martin-Martorell P, De Julián M, et al. Predictive and prognostic clinical and pathological factors of nivolumab efficacy in non-small-cell lung cancer patients. Clin Transl Oncol 2018;20:1072-9.

114.Jeanson A, Tomasini P, Souquet-Bressand M, et al. Efficacy of Immune Checkpoint Inhibitors in KRAS-Mutant NonSmall Cell Lung Cancer (NSCLC). J Thorac Oncol 2019;14:1095-101.

115. Torralvo J, Friedlaender A, Achard V, et al. The activity of immune checkpoint inhibition in kras mutated nonsmall cell lung cancer: A single centre experience. Cancer Genomics Proteomics 2019;16:577-82.

116. Gianoncelli L, Spitaleri G, Passaro A, et al. Efficacy of Anti-PD1/PD-L1 Therapy (IO) in KRAS Mutant Nonsmall Cell Lung Cancer Patients: A Retrospective Analysis. Anticancer Res 2020;40:427-33.

117. Arbour KC, Jordan E, Kim HR, et al. Effects of Cooccurring Genomic Alterations on Outcomes in Patients 
With KRAS-Mutant Non-Small Cell Lung Cancer. Clin Cancer Res 2018;24:334-40.

118. Mitchell TC, Hamid O, Smith DC, et al. Epacadostat Plus Pembrolizumab in Patients With Advanced Solid Tumors: Phase I Results From a Multicenter, Open-Label Phase I/II Trial (ECHO-202/KEYNOTE-037). J Clin Oncol 2018;36:3223-30.

119.Skoulidis F, Byers LA, Diao L, et al. Co-occurring genomic alterations define major subsets of KRAS-mutant lung adenocarcinoma with distinct biology, immune profiles, and therapeutic vulnerabilities. Cancer Discov 2015;5:860-77.

120. Koyama S, Akbay EA, Li YY, et al. STK11/LKB1 deficiency promotes neutrophil recruitment and proinflammatory cytokine production to suppress T-cell activity in the lung tumor microenvironment. Cancer Res 2016;76:999-1008.

121. Kadara H, Choi M, Zhang J, et al. Whole-exome sequencing and immune profiling of early-stage lung adenocarcinoma with fully annotated clinical follow-up. Ann Oncol 2017;28:75-82.

122. Skoulidis F, Goldberg ME, Greenawalt DM, et al. STK11/ LKB1 Mutations and PD-1 Inhibitor Resistance in KRAS- Mutant Lung Adenocarcinoma. Cancer Discov 2018;8:822-35.

123. Kim Y, Kim HC, Lee YH, et al. Comprehensive Clinical and Genetic Characterization of Hyperprogression Based on Volumetry in Advanced Non-Small Cell Lung Cancer Treated With Immune Checkpoint Inhibitor. J Thorac Oncol 2019;14:1608-18.

124. Schabath MB, Welsh EA, Fulp WJ, et al. Differential association of STK11 and TP53 with KRAS mutationassociated gene expression, proliferation and immune surveillance in lung adenocarcinoma. Oncogene 2016;35:3209-16.

125. Heo JY, Park C, Keam B, et al. The efficacy of immune checkpoint inhibitors in anaplastic lymphoma kinasepositive non-small cell lung cancer. Thorac Cancer 2019;10:2117-23.

126. Ota K, Azuma K, Kawahara A, et al. Induction of PDL1 Expression by the EML4-ALK Oncoprotein and Downstream Signaling Pathways in Non-Small Cell Lung Cancer. Clin Cancer Res 2015;21:4014-21.

127. Solomon BJ, Kim DW, Wu YL, et al. Final overall survival analysis from a study comparing first-line crizotinib versus chemotherapy in alk-mutation-positive non-small-cell lung cancer. J Clin Oncol 2018;36:2251-8.

128. Mok T, Camidge DR, Gadgeel SM, et al. Updated overall survival and final progression-free survival data for patients with treatment-naive advanced ALK-positive non-small-cell lung cancer in the ALEX study. Ann Oncol 2020;31:1056-64.

129. Spigel DR, Reynolds C, Waterhouse D, et al. Phase 1/2 Study of the Safety and Tolerability of Nivolumab Plus Crizotinib for the First-Line Treatment of Anaplastic Lymphoma Kinase Translocation-Positive Advanced NonSmall Cell Lung Cancer (CheckMate 370). J Thorac Oncol 2018;13:682-8.

130. Patel SP, Pakkala S, Pennell NA, et al. Phase Ib Study of Crizotinib plus Pembrolizumab in Patients with Previously Untreated Advanced Non-Small Cell Lung Cancer with ALK Translocation. Oncologist 2020;25:562-e1012.

131.Felip E, de Braud FG, Maur M, et al. Ceritinib plus Nivolumab in Patients with Advanced ALK-Rearranged Non-Small Cell Lung Cancer: Results of an OpenLabel, Multicenter, Phase 1B Study. J Thorac Oncol 2020;15:392-403.

132.Kim DW, Gadgeel SM, Gettinger SN, et al. Safety and clinical activity results from a phase Ib study of alectinib plus atezolizumab in ALK+ advanced NSCLC (aNSCLC). J Clin Oncol 2018;36:9009.

133. Hong S, Chen N, Fang W, et al. Upregulation of PDL1 by EML4-ALK fusion protein mediates the immune escape in ALK positive NSCLC: Implication for optional anti-PD-1/PD-L1 immune therapy for ALK-TKIs sensitive and resistant NSCLC patients. Oncoimmunology 2015;5:e1094598.

134. Shaw AT, Lee SH, Ramalingam SS, et al. Avelumab (antiPD-L1) in combination with crizotinib or lorlatinib in patients with previously treated advanced NSLCL: Phase Ib results from JAVELIN Lung 101. J Clin Oncol 2018;36:9008.

135.Lin JJ, Chin E, Yeap BY, et al. Increased Hepatotoxicity Associated with Sequential Immune Checkpoint Inhibitor and Crizotinib Therapy in Patients with Non-Small Cell Lung Cancer. J Thorac Oncol 2019;14:135-40.

136.Leonetti A, Facchinetti F, Rossi G, et al. BRAF in nonsmall cell lung cancer (NSCLC): pickaxing another brick in the wall. Cancer Treat Rev 2018;66:82-94.

137.Planchard D, Smit EF, Groen HJM, et al. Dabrafenib plus trametinib in patients with previously untreated BRAF V600E -mutant metastatic non-small-cell lung cancer: an open-label, phase 2 trial. Lancet Oncol 2017;18:1307-16.

138. Rihawi K, Giannarelli D, Galetta D, et al. BRAF Mutant NSCLC and Immune Checkpoint Inhibitors: Results From a Real-World Experience. J Thorac Oncol 
2019;14:e57-9.

139. Guisier F, Dubos-Arvis C, Viñas F, et al. Efficacy and Safety of Anti-PD-1 Immunotherapy in Patients With Advanced NSCLC With BRAF, HER2, or MET Mutations or RET Translocation: GFPC 01-2018. J Thorac Oncol 2020;15:628-36.

140.Dudnik E, Peled N, Nechushtan H, et al. BRAF Mutant Lung Cancer: Programmed Death Ligand 1 Expression, Tumor Mutational Burden, Microsatellite Instability Status, and Response to Immune Check-Point Inhibitors. J Thorac Oncol 2018;13:1128-37.

141.Dudnik E, Bshara E, Grubstein A, et al. Rare targetable drivers (RTDs) in non-small cell lung cancer (NSCLC): Outcomes with immune check-point inhibitors (ICPi). Lung Cancer 2018;124:117-24.

142.Lamberti G, Spurr LF, Li Y, et al. Clinicopathological and genomic correlates of programmed cell death ligand 1 (PD-L1) expression in nonsquamous non-small-cell lung cancer. Ann Oncol 2020;31:807-14.

143. Sabari JK, Leonardi GC, Shu CA, et al. PD-L1 expression, tumor mutational burden, and response to immunotherapy in patients with MET exon 14 altered lung cancers. Ann Oncol 2018;29:2085-91.

144. Reis H, Metzenmacher M, Goetz M, et al. MET Expression in Advanced Non-Small-Cell Lung Cancer: Effect on Clinical Outcomes of Chemotherapy, Targeted Therapy, and Immunotherapy. Clin Lung Cancer 2018;19:e441-63.

145.Dall'Olio FG, Maggio I, Massucci M, et al. ECOG

Cite this article as: Guaitoli G, Tiseo M, Di Maio M, Friboulet L, Facchinetti F. Immune checkpoint inhibitors in oncogene-addicted non-small cell lung cancer: a systematic review and meta-analysis. Transl Lung Cancer Res 2021;10(6):2890-2916. doi: 10.21037/tlcr-20-941 performance status $\geq 2$ as a prognostic factor in patients with advanced non small cell lung cancer treated with immune checkpoint inhibitors- A systematic review and meta-analysis of real world data. Lung Cancer 2020;145:95-104.

146. Herbst RS, Tsuboi M, John T, et al. Osimertinib as adjuvant therapy in patients (pts) with stage IB-IIIA EGFR mutation (EGFRm) positive NSCLC after complete tumor resection: ADAURA. J Clin Oncol 2020;18:LBA5.

147.Wu YL, Zhong W, Wang Q, et al. CTONG1104: Adjuvant gefitinib versus chemotherapy for resected N1N2 NSCLC with EGFR mutation-Final overall survival analysis of the randomized phase III trial 1 analysis of the randomized phase III trial. J Clin Oncol 2020;15:9005.

148. Cascone T, William NW, Weissferdt A, et al. Neoadjuvant nivolumab (N) or nivolumab plus ipilimumab (NI) for resectable non-small cell lung cancer (NSCLC): Clinical and correlative results from the NEOSTAR study. J Clin Oncol 2019;15: 8504.

149. Shu CA, Gainor JF, Awad MM, et al. Neoadjuvant atezolizumab and chemotherapy in patients with resectable non-small-cell lung cancer: an open-label, multicentre, single-arm, phase 2 trial. Lancet Oncol 2020;21:786-95.

150.Ahn MJ, Park S, Jung HA, et al. Phase II, prospective single-arm study of adjuvant pembrolizumab in N2 positive non-small cell lung cancer (NSCLC) treated with neoadjuvant concurrent chemoradiotherapy followed by curative resection: Preliminary results. J Clin Oncol $2019 ; 15: 8520$. 